\title{
Spatial and Temporal Patterns of Muscle Cleavage in the Chick Thigh and Their Value as Criteria for Homology
}

\author{
SALLY SCHROETER AND KATHRYN W. TOSNEY \\ Department of Biology, University of Michigan, Ann Arbor, Michigan 48109-1048
}

\begin{abstract}
Regions of lower cell density, called cleavage zones, emerge within the dorsal and ventral muscle masses in the vertebrate limb to separate distinct muscles. In the chick thigh, the stereotyped patterns of separation have been broadly outlined, but differences in interpretation exist because no criteria for separation have been defined, and the tissues of the limb are indistinct early in development. We have examined the cleavage process using modern applications of light microscopy and immunocytochemistry to completely detail the spatial and temporal progression of cleavage in stage $27-32$ embryos. We find that each muscle has a complex but characteristic pattern of separation along the proximodistal axis. The complex pattern of separation is not related to the positions of muscles within the thigh, locations of blood vessels, activity patterns of muscles, or innervation patterns. The initial separation patterns are more straightforward than later separations and may be of value in determining the phylogenetic history of limb muscles since the same patterns are common to many tetrapods. Our detailed documentation clarifies the ontogeny of the thigh musculature and reveals more complex separation patterns between muscles than previously described.
\end{abstract}

\section{INTRODUCTION}

Tetrapod limb muscles are derived from two condensations of muscle cells located dorsal and ventral to the cartilaginous anlagen that will form the central bone(s) of each limb segment. Muscles become separated from one another as regions of increased extracellular space, called cleavage zones, gradually emerge between muscle primordia in an orderly manner. Such patterns of separation have been described in the mouse (Lance Jones, 1979), opossum (Cheng, 1955), human (Čihák, 1972), axolotl (Grim and Carlson, 1974), newt (Chen, 1935), lizard (Romer, 1942), turtle (Walker, 1947), and chick (Romer, 1927; Wortham, 1948; Sullivan, 1962; Shellswell and Wolpert, 1977; Pautou et al., 1982; Schroeter, 1989; Schroeter and Tosney, 1989, 1991).

The stereotyped patterns of cleavage in the chick thigh were first recognized and broadly outlined by Romer in 1927. His study was based on only a few time points and did not have the benefit of modern histological staining techniques. He modified the description slightly following a study on reptilian muscle develop- ment, but the modifications were based on muscle homologies rather than further, direct observations of sectioned material (Romer, 1942). Since no criteria for separation were defined in Romer's study, controversies have arisen over interpretations of his descriptions. In addition, morphological features that could provide valid criteria can be interpreted in more than one way because the condensations of muscle cells composing the primordia of individual muscles are indistinct and blend with the surrounding mesenchyme to a great extent. The tissues were especially indistinct in the slides used for Romer's 1927 study because of the lack of differential staining, although the sections themselves and the tissue preservation were of high quality. A more detailed study of muscle morphogenesis is clearly needed.

A detailed description of muscle separation is important for two reasons. First, morphogenetic features are often used as the basis for morphological homologies (see, for instance, Oster et al., 1988; Albcrch, 1980; Fink, 1982, 1988; Rowe, 1986). As muscle masses subdivide, indentations and a decrease in cell packing density between muscle primordia give the masses a lobed appearance. The lobed profiles and the gross patterns of separation seem to reflect generally the phylogenetic history of limb muscles. Second, morphogenesis of muscles may be interrelated with other features of development, and a precise description of muscle formation will contribute to a more complete understanding of limb development.

The present paper characterizes the precise spatial and temporal patterns of separation of muscles in the chick thigh. We viewed cross sections of thighs using conventional light microscopy and immunocytochemistry to examine the morphological changes in individual muscle primordia as they separate. The advantages of our study over previous ones are the use of a large number of embryos to provide a continuum of intermediate phases of separation, the use of several modern staining techniques to reveal cellular and extracellular details, the definition of spatial and temporal changes in distributions of different cell types based on staining characteristics, and the integration of modern terminology that is not based on supposed homologies.

The basis for the ability to describe the formation of individual muscles with precision is derived from the

Received May 23, 1990. Accepted February 25, 1991.

Sally Schroeter is now at Department of Physiology, Emory University, Atlanta, GA 30322 . Address reprint requests there. 
results of our previous ultrastructural study (Schroeter and Tosney, 1991). We described a sequence of cellular changes that accompanies the progression of one particular cleavage zone along the proximodistal axis of the limb. As two muscles separate, the region between them is characterized by a progressive loss of cell-cell interactions, an increase in extracellular space, a transformation of mesenchymal cells to a stellate morphology, and a disappearance of muscle cells. These changes emerge gradually along the future boundary between two muscles and progress either from proximal to distal or distal to proximal until the separations are complete. These definitive characteristics seen at the ultrastructural level are the basis for our ability to describe cleavage at the light level in a precise way.

Despite the speed and complexity of this large, threedimensional rearrangement of cells, we were able to determine the timing, order, and directions in which muscles cleave. We found that the 22 muscles of the thigh emerge from the dorsal and ventral muscle masses over a period of about 1.5 days, from stages 27 to 30 . Muscles never separate from the proximodistal center outwards; instead, each pair of muscles separates along the proximodistal axis from or toward the muscle origins. These separations appear in a complex sequence instead of a simple binary or trinary set of separations. Different muscles cleave in different directions, but the pattern and sequence of cleavage is repeated in each embryo.

A preliminary report of these results has appcared elsewhere (Schroeter, 1989; Schroeter and Tosney, 1989).

\section{MATERIALS AND METHODS}

This study of the thigh of chicken embryos begins with stage 27 , when premuscle and precartilage condensations can be clearly distinguished with the light microscope, and extends through stage 32.5 , when all muscles of the thigh are distinct. In conjunction with descriptions of muscle morphogenesis, some observations on skeletal formation and innervation are included to clarify muscle topographical relationships. Reference is made to different cell types; but their detailed morphology, distributions, and interactions are described in detail in an ultrastructural study of muscle separation (Schroeter and Tosney, 1987, 1991). The thigh musculature of two 6-week-old chicks was also examined to provide a clear reference for the examination of the embryos.

\section{Histology}

Hind limbs and attached medial tissues were dissected from White Leghorn chicken embryos. The tissue was fixed, dehydrated in graded ethanols, embedded into paraffin from xylenes or Hemo-DE, and sectioned at 9-12 $\mu \mathrm{m}$. Twenty-three embryos were fixed in Carnoy's and Bouin's fixatives (Humason, 1972) and stained with Alcian blue, cresyl violet, and eosin. Serial, $25 \mu \mathrm{m}$ plastic sections of thighs prepared as in Schroeter and Tosney (1991) were also examined; cellular detail was revealed in these sections by postfixation in osmium.

A subset of six embryos was fixed in a solution of $4 \%$ formaldehyde, $2 \%$ calcium chloride, and $0.5 \%$ cetylpyridinium chloride (CPC) to preserve glycosaminogly- cans (Pratt et al., 1975). These embryos were stained with Alcian blue ( $\mathrm{pH} 2.6$ ) to facilitate the distinction of muscle and the surrounding precartilage and other connective tissues. Muscle tissue remained unstained while intercellular areas of the surrounding tissue and skeletal elements stained blue. Alcian blue is a cationic dye that binds glycosaminoglycans (Derby and Pintar, 1978) which are produced by chondrogenic cells in the limb as early as stage 21 (Hallmann et al., 1987). The morphogenesis of the skeletal elements was revealed by an increasing intensity of blue staining and by a transformation of a fibrous pattern to a solid pattern over time.

A second subset of 11 embryos was fixed in Zenker formol and stained with either the Everett and Miller (1973) adaptation of the Mallory trichrome stain or a modified version of the Milligan trichrome stain (Humason, 1972). Alcian blue was included in the staining sequence after acid fuschin to stain extracellular matrix molecules. Without this addition, the embryonic muscle and connective tissues were predominantly pink and were not distinguishable.

\section{Immunocytochemistry}

Six embryos were prepared for staining with a monoclonal antibody to sarcomere myosin, MF 20 (Bader et al., 1982). This antibody specifically labels differentiating muscle cells. We used the observations on the distribution of muscle cells revealed by immunostaining of frozen sections to confirm the identification of the boundaries between different tissues. Embryos were fixed for $1 \mathrm{hr}$ in $2 \%$ paraformaldehyde in phosphate-buffered saline (PBS) with $0.5 \% \mathrm{CPC}$ at room temperature, rinsed in 5\% sucrose, incubated in $20 \%$

\begin{tabular}{ll}
\hline & \multicolumn{1}{c}{ Abbreviations } \\
AIL & iliotibialis lateralis preacetabularis \\
AMB & ambiens \\
CF & caudofemoralis \\
CIF & caudo-ilio-femoralis \\
f & femur \\
FCL & flexor cruris lateralis \\
FCLA & FCL pars accessoria \\
FCLP & FCL pars pelvica \\
FCM & flexor cruris medialis \\
FT & femorotibialis \\
FTE & FT externus \\
FTI & FT internus \\
FTM & FT medialis \\
IC & iliotibialis cranialis \\
IF & iliofibularis \\
IFE & iliofemoralis externus \\
IFI & iliofemoralis internus \\
il & ilium \\
IL & iliotibialis lateralis \\
ILF & iliofemoralis \\
is & ischium \\
ISF & ischiofemoralis \\
ITC & iliotrochantericus caudalis \\
ITCR & iliotrochantericus cranialis \\
ITM & iliotrochantericus medius \\
OBT & obturatorius \\
OBTL & OBT lateralis \\
OBTM & OBT medialis \\
p & pubis \\
PIF & pubo-ischio-femoralis \\
PIFL & PIF pars lateralis \\
PIFM & PIF pars medialis \\
PIL & iliotibialis lateralis postacetabularis \\
&
\end{tabular}




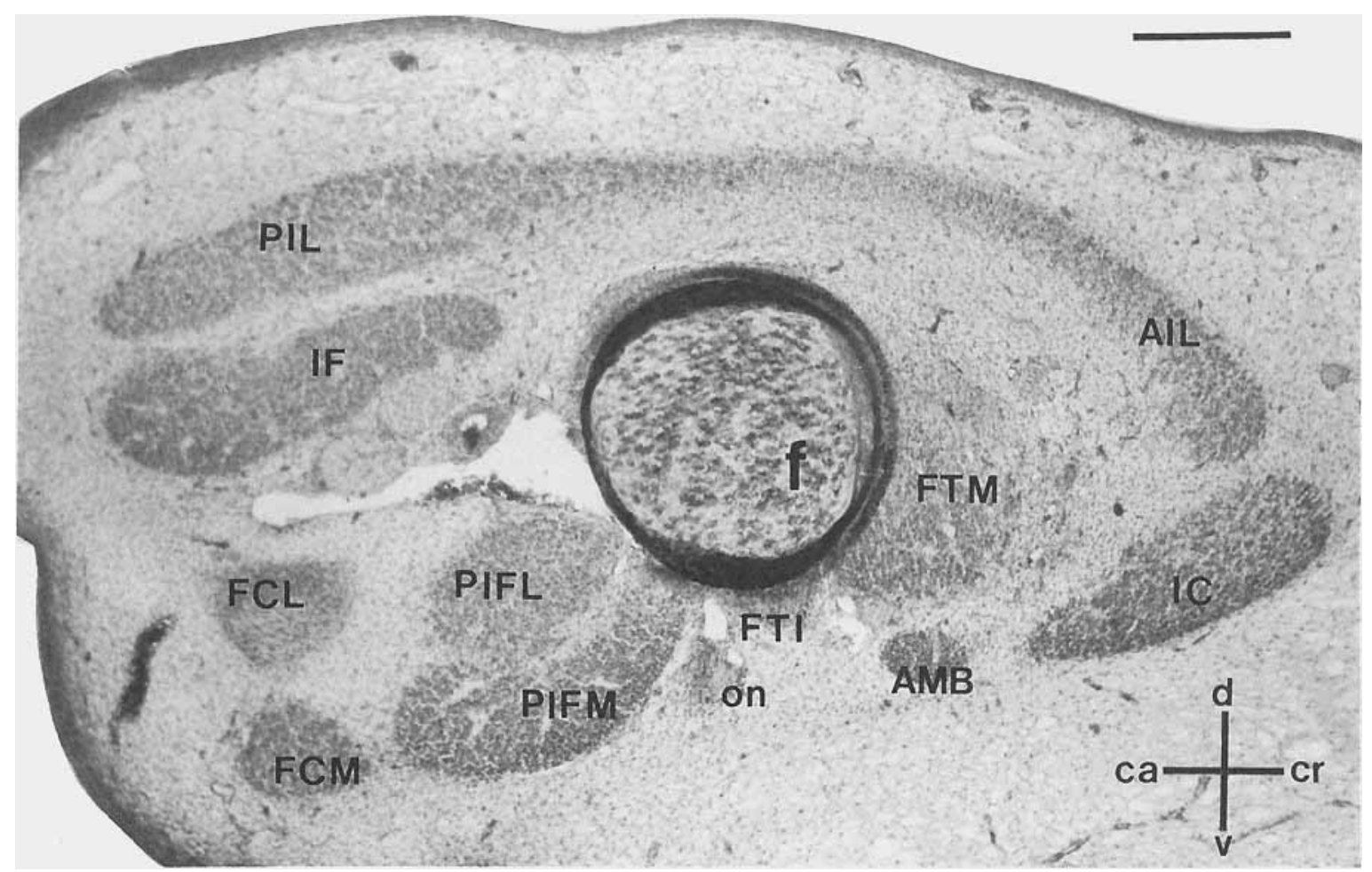

Fig. 1. Cross section through the mid-thigh region after cleavage (stage 30) illustrating anatomical orientations in the embryo. All muscles are distinct at this stage, and the spatial arrangement of the muscles is similar to that in the adult. The iliotibialis lateralis covers the dorsal surface of the thigh, and the neighboring iliotibialis crani- alis is the most cranial muscle. The two pubo-ischio-femorales and the femorotibialis internus lie ventrally, and the flexor cruris lateralis is one of the most caudal thigh muscles. Muscle names are from Nomina Anatomica Avium (Baumel et al., 1979). on, Obturator nerve. Bar = $100 \mu \mathrm{m}$. sucrose, and embedded and frozen in OCT (Tissue Tek). Each thigh contained a piece of hair inserted underneath the ectoderm, parallel to the femur, to facilitate perpendicular orientation when sectioning. Transverse sections were cut on a cryostat at $6-8 \mu \mathrm{m}$, mounted on acid-cleaned slides double-subbed with gelatin, and stored at $-80^{\circ} \mathrm{C}$ for up to 2 weeks.

Sections were blocked in $1 \%$ bovine serum albumin (BSA) in PBS (pH 7.2) for 5 min at room temperature, incubated with primary antibody (1:10 dilution) for $1 \mathrm{~h}$ at $37^{\circ} \mathrm{C}$, rinsed in PBS for $10 \mathrm{~min}$, and blocked again. A biotinylated secondary antibody was applied for $30 \mathrm{~min}$ at room temperature (1:40 sheep anti mouse IgG from Amersham). The sections were rinsed, blocked, and then incubated for $30 \mathrm{~min}$ with Texas Red-avidin (1:50, Amersham) and rinsed. The primary antibody was omitted from some sections as a control.

\section{Graphic Representations of Progression of Cleavage Zones}

Three dimensional reconstructions of the thigh were made using the computer software Cellmate and Mapper (Bioquant) and a Zenith computer, a Leitz microscope with a motor-driven stage, a Matrox graphics board, a Hewlett Packard plotter, and a NEC color monitor. Sections at approximately $40-\mu \mathrm{m}$ intervals were digitized and aligned by superimposing the external contours of the limb. Mat-board scale models of the skeletal elements were made by cutting out shapes of skeletal elements from templates of each section and gluing them together in sequence with epoxy. The wire-frame plots generated by computer and the matboard models were used to make anatomical drawings of stage 29 and stage 32.5 thighs depicting the limb during and after cleavage. These drawings illustrate the series of morphogenetic changes of the musculature as well as the spatial relationships between muscles and skeletal elements.

The progress of the cleavage zones was graphically documented for 10 embryos. Camera-lucida drawings were made of every section, and each muscle and its relationship to its neighbors was systematically translated to a graphic display. Individual sections were represented on the $\mathrm{x}$ axis, and the presence and phase of cleavage for each muscle was recorded for each section. This ensured that the same criteria for separation were used for each muscle and that the progress of the separations could be compared directly at a range of stages of development.

\section{RESULTS}

\section{Anatomical Orientations}

The anatomical orientations used in the following descriptions of embryonic thigh musculature are illustrated in Figure 1. The nomenclature is that found in 
TABLE 1. Synonymy and abbreviations of avian thigh muscles

\begin{tabular}{|c|c|c|c|}
\hline $\begin{array}{l}\text { George and Berger } \\
(1966)\end{array}$ & $\begin{array}{l}\text { Romer } \\
(1927)\end{array}$ & $\begin{array}{c}\text { Nomina Anatomica Avium } \\
\text { Baumel (1979) }\end{array}$ & $\begin{array}{l}\text { Abbrevia- } \\
\text { tions }\end{array}$ \\
\hline Iliotibialis & Iliotibialis & $\begin{array}{l}\text { Iliotibialis lateralis } \\
\text { postacetabularis } \\
\text { preacetabularis }\end{array}$ & $\begin{array}{l}\text { IL } \\
\text { PIL } \\
\text { AIL }\end{array}$ \\
\hline Biceps femoris & Iliofibularis & lliofibularis & IF \\
\hline Sartorius & Sartorius & Iliotibialis cranialis & IC \\
\hline Ambiens & Ambiens & Ambiens & AMB \\
\hline $\begin{array}{l}\text { Femorotibialis } \\
\text { externus } \\
\text { internus } \\
\text { medius }\end{array}$ & Femorotibialis & $\begin{array}{l}\text { Femorotibialis } \\
\text { externus } \\
\text { internus } \\
\text { medialis }\end{array}$ & $\begin{array}{l}\text { FT } \\
\text { FTE } \\
\text { FTI } \\
\text { FTM }\end{array}$ \\
\hline Iliacus & Iliofemoralis internus & Iliofemoralis internus & IFI \\
\hline Iliotrochantericus posterior & Iliotrochantericus I & Iliotrochantericus caudalis & ITC \\
\hline Iliotrochantericus anterior & Iliotrochantericus II & Iliotrochantericus cranialis & ITCR \\
\hline Iliotrochantericus medius & Iliotrochantericus III & Iliotrochantericus medius & ITM \\
\hline Gluteus medius et minimus & Iliofemoralis externus & Iliofemoralis externus & IFE \\
\hline Obturator externus and internus & Obturator externus and internus & Obturatorius lateralis and medialis & OBT (L \& M) \\
\hline Adductor brevis & Pubo-ischio-femoralis externus & Pubo-ischio-femoralis pars lateralis & PIFL \\
\hline Adductor longus & Pubo-ischio-femoralis internus & Pubo-ischio-femoralis pars medialis & PIFM \\
\hline Ischiofemoralis & Ischiofemoralis & Ischiofemoralis & ISF \\
\hline Semimembranosus & Ischiof lexorius & Flexor cruris medialis & FCM \\
\hline Semitendinosus & Caudilioflexorius & Flexor cruris lateralis pars pelvica & FCLP \\
\hline Accessorius semitendinosi & Accessorius & Flexor cruris lateralis pars accessoria & FCLA \\
\hline Piriformis & Caudo-ilio-femoralis & Caudo-ilio-femoralis & CIF \\
\hline pars caudofemoralis & & Caudofemoralis & $\mathrm{CF}$ \\
\hline pars iliofemoralis & & Iliofemoralis & ILF \\
\hline
\end{tabular}

Nomina Anatomica Avium (Baumel et al., 1979; see Table 1). After muscle separation, in a stage $30 \mathrm{em}-$ bryo, the iliotibialis lateralis covers the dorsal surface of the thigh, and the neighboring iliotibialis cranialis is the most cranial (anterior) muscle. The two puboischio-femorales and the femorotibialis internus lie ventrally, and the caudo-ilio-femoralis (not visible) and flexor cruris lateralis are the most caudal (posterior) muscles of the thigh.

The anatomical orientations of the musculature in the embryo are different from that in the adult. In the adult (Fig. 2), the iliotibialis lateralis lies laterally instead of dorsally as in the embryo, and the pubo-ischiofemoralis medialis is named for its medial location in the adult but lies ventrally in the embryonic thigh. Muscles lying caudal (posterior) and cranial (anterior) in the embryo are arranged similarly in the adult. The following description will use the relative terms "deep" and "superficial" to mean closer or farther away from the femur in describing the relative positions of muscles, and "dorsal" and "ventral" will be reserved for references to the derivation of muscles from the dorsal and ventral muscle masses.

\section{Before Cleavage}

Before the muscle masses start to separate into individual muscles during stage 27, they appear as homogeneous condensations of cells at the light microscopic level (Fig. 3). Most of these closely packed cells are muscle cells which are rounded and pink. Fewer, elongated mesenchymal cells are interspersed among the muscle cells. The dorsal and ventral masses are separated cranially by a branch of the crural nerve trunk, the femoral nerve, and caudally by the ischiadic nerve trunk. The masses are separated from the ectoderm by a stellate network of mesenchymal cells with extensive processes. Developing blood vessels pervade this network between the superficial surfaces of the muscle masses and the ectoderm.

Boundaries of muscle tissue are equally distinct near differentiating skeletal elements. The cartilaginous anlage of the femur appears as a central whorl of cells embedded in a matrix that stains darkly with Alcian blue. The pelvic girdle anlage stains darkly with Alcian blue in its most mature areas centering around the acetabulum where cells are embedded in a matrix resembling that of the femur, but the cranial and caudal extents of the girdle are not distinct at this time (Fig. 4). Immature parts of the pelvic primordia are composed of fibrous, Alcian-blue-staining connective tissue that blends into the surrounding mesenchyme. As the embryo matures, the boundaries of the skeletal elements become well-defined and the Alcian blue staining is granular (Fig. 5). Precise sites of future muscle origins are indistinct at younger stages since tendons are still unorganized, but the extent of muscle tissue can be discerned by the absence of Alcian bluestaining matrix between muscle cells.

\section{Definition and Identification of the Cleavage Zone}

The region between separating muscles is called a cleavage zone. It is characterized by a series of cellular changes that emerge in an orderly manner along the proximodistal axis of the limb. A schematic diagram of a progressing cleavage zone is shown in Figure 6 . As a cleavage zone progresses, the cells between individual muscles appear to become less closely packed; and the boundaries of muscles become defined by a gradual increase in extracellular space and the appearance of stellate mesenchymal cells between anlagen. These changes can be seen at the light level and have been 

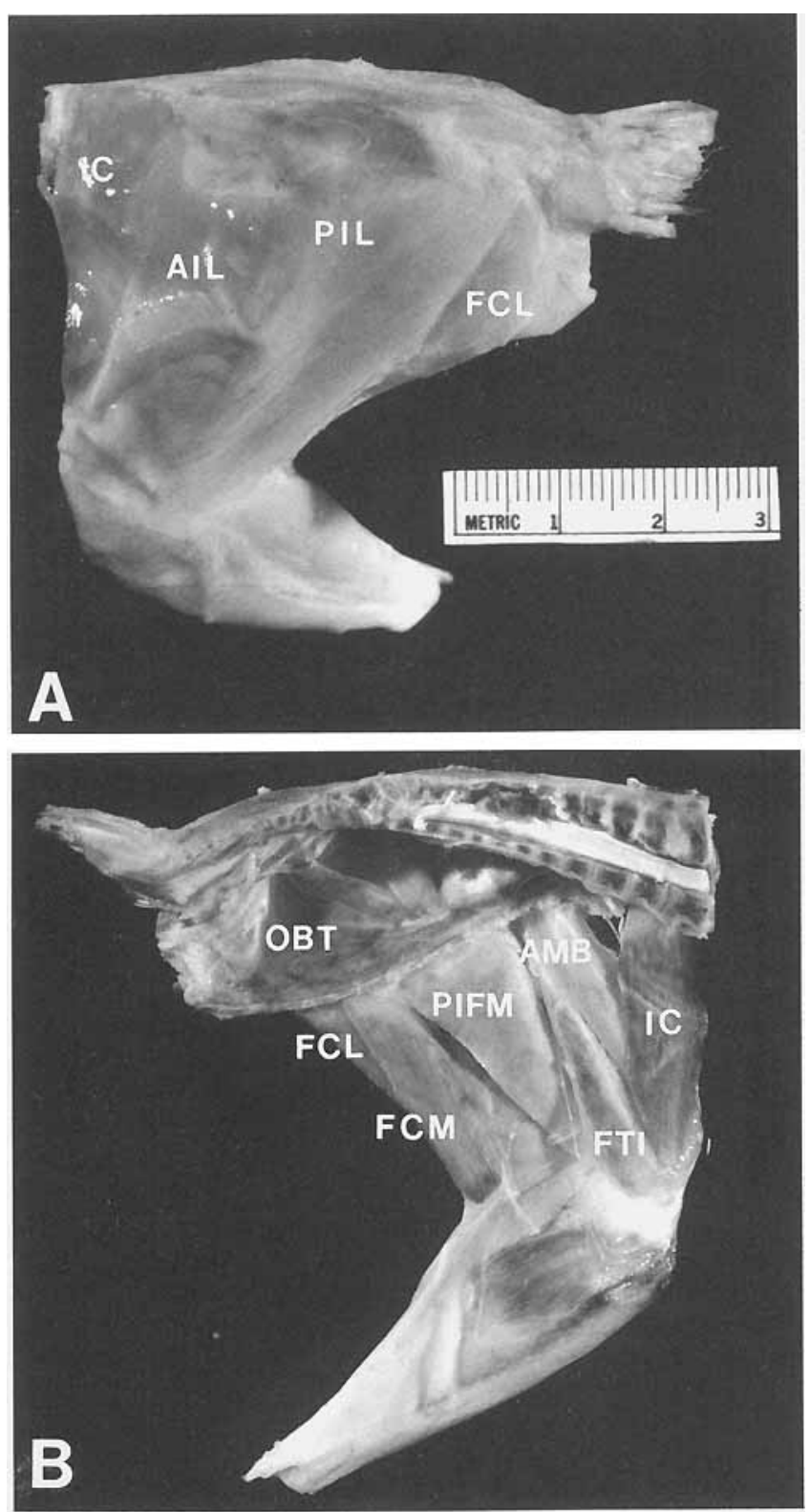

Fig. 2. Muscles of the left thigh in a 6-week-old chick illustrating anatomical orientations of muscles of the adult. A: Lateral view. B: Medial view. The iliotibialis lateralis lies laterally instead of dorsally as in the embryo, and the pubo-ischio-femoralis medialis is named for its medial location in the adult but lies ventrally in the embryonic thigh (see Fig. 1).

further characterized and defined at the electron-microscopic level (Schroeter and Tosney, 1991).

Distinct and reproducible criteria allowed the unequivocal definition of muscle anlagen and cleavage zones. The earliest indication that a portion of the muscle mass was destined to become a particular muscle was the appearance of muscle nerves within a corresponding region of the muscle masses (Fig. 7). The positions of muscle nerves as well as muscle fiber directions were particularly helpful in identifying muscle primordia that are very closely apposed and remain so in their adult form. Next, indentations or a tapering of some muscles (Fig. 8) were evident at their cleaving surfaces as muscles appeared to pinch off from one another. In all cases, a feature that distinguished the muscle tissue from connective tissue was the contrast in staining by Alcian blue: little if any Alcian blue staining was seen in muscle during cleavage, while the surrounding extracellular matrix (ECM) of mesenchymal tissue and skeletal elements stained deeply. As muscles cleaved, the ECM between individual muscles also stained blue, although the staining did not presage the disappearance of muscle cells from these areas. In addition, the blue staining of skeletal elements further defined the relative positions of muscle anlagen. The known origins of muscles on skeletal elements from older embryos and adult birds aided in the identification of muscle anlagen in younger embryos where muscles lay near the adult sites of attachment.

These criteria for identifying muscle anlagen and cleavage zones in paraffin sections were developed by comparing the paraffin sections with frozen sections in which muscle cells were specifically labeled. The distribution of rounded, pink cells with little or no blue staining between them seen in paraffin sections correlated precisely with the distribution of labeled cells in the frozen sections stained with a monoclonal antibody specific for sarcomere myosin (Bader et al., 1982). Figure 8 illustrates muscle cells labeled with this antibody in the presumptive cleavage zone between the iliotibialis lateralis and cranialis and between the iliotibialis cranialis and ambiens.

The progression of cleavage zones is not closely correlated with the outward morphology of the embryonic limb. The changes that accompany the emergence of individual muscles appear in a constant stereotyped sequence, but they do not repeatedly correspond with a particular stage of development. The following results, therefore, are reported by focusing on the sequence in which individual separations are complete rather than on the stage of development as assessed by Hamburger and Hamilton criteria. There is some individual variation between embryos in the initiation of a particular cleavage zone and the rate at which it progresses, so we defined the sequence of separations using the most overt characteristic, the completion of a separation. The sequence reported here is based on average stages representing early cleavages, stage 28 ; later cleavages, stage 29; and latest cleavages, stage 30 .

\section{Definition of Groups}

For ease of description, the muscles of the thigh have been grouped according to their locations during development. The six groups, the criteria for grouping, and their spatial relationships are described below. No evolutionary or functional relationships are implied by the inclusion of a muscle in a particular group.

Muscles derived from the dorsal muscle mass can be divided into an iliotibialis group, a deep proximal group, and a femorotibialis group. The iliotibialis group includes the iliotibialis cranialis, iliotibialis lateralis, iliofibularis, and ambiens (Figs. 1, 2). These muscles originate on the ilium and pectineal process and cover the dorsal surface of the embryonic thigh and the dorsolateral surface of the adult thigh. They are all 

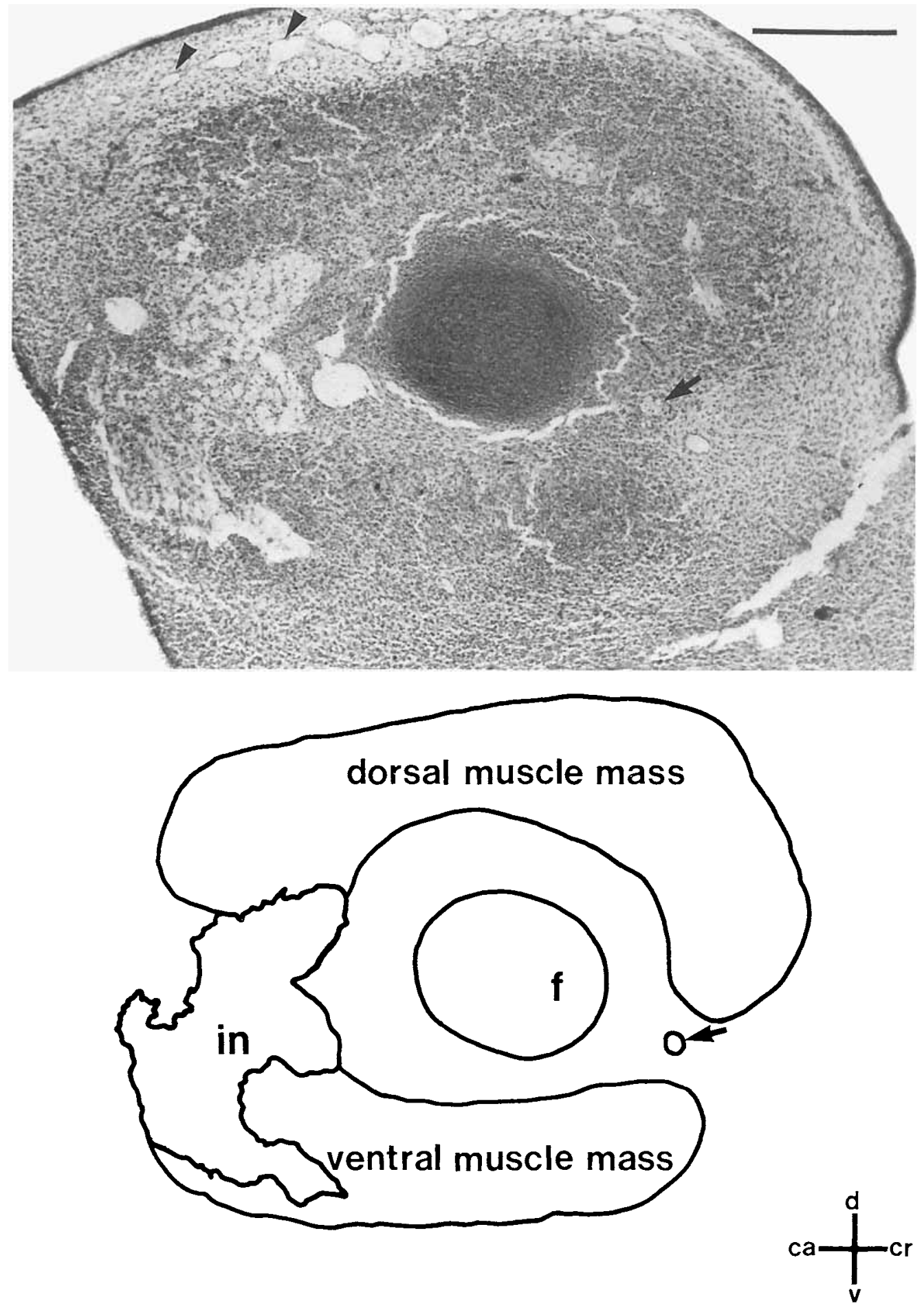

Fig. 3. Cross section through the mid-thigh region before cleavage (stage 27). Muscles appear as condensations of rounded, pink cells in sections stained with cresyl violet, Alcian blue, and eosin. The location of muscle tissue is indicated in the camera-lucida drawing below. The dorsal muscle mass is separated from the ventral mass by the ischiadic nerve trunk (in) caudally. Cranially a branch of the femoral nerve (arrow) and a mass of mesenchymal cells interspersed with Alcian blue-stained extracellular matrix lie between the muscle masses. This region between the masses contains more extracellular space and thinner cells surrounding the nerve than in the muscle tissue in the photograph. Blood vessels (arrowheads) pervade the network of mesenchymal tissue between the muscles. Bar $=100 \mu \mathrm{m}$. 


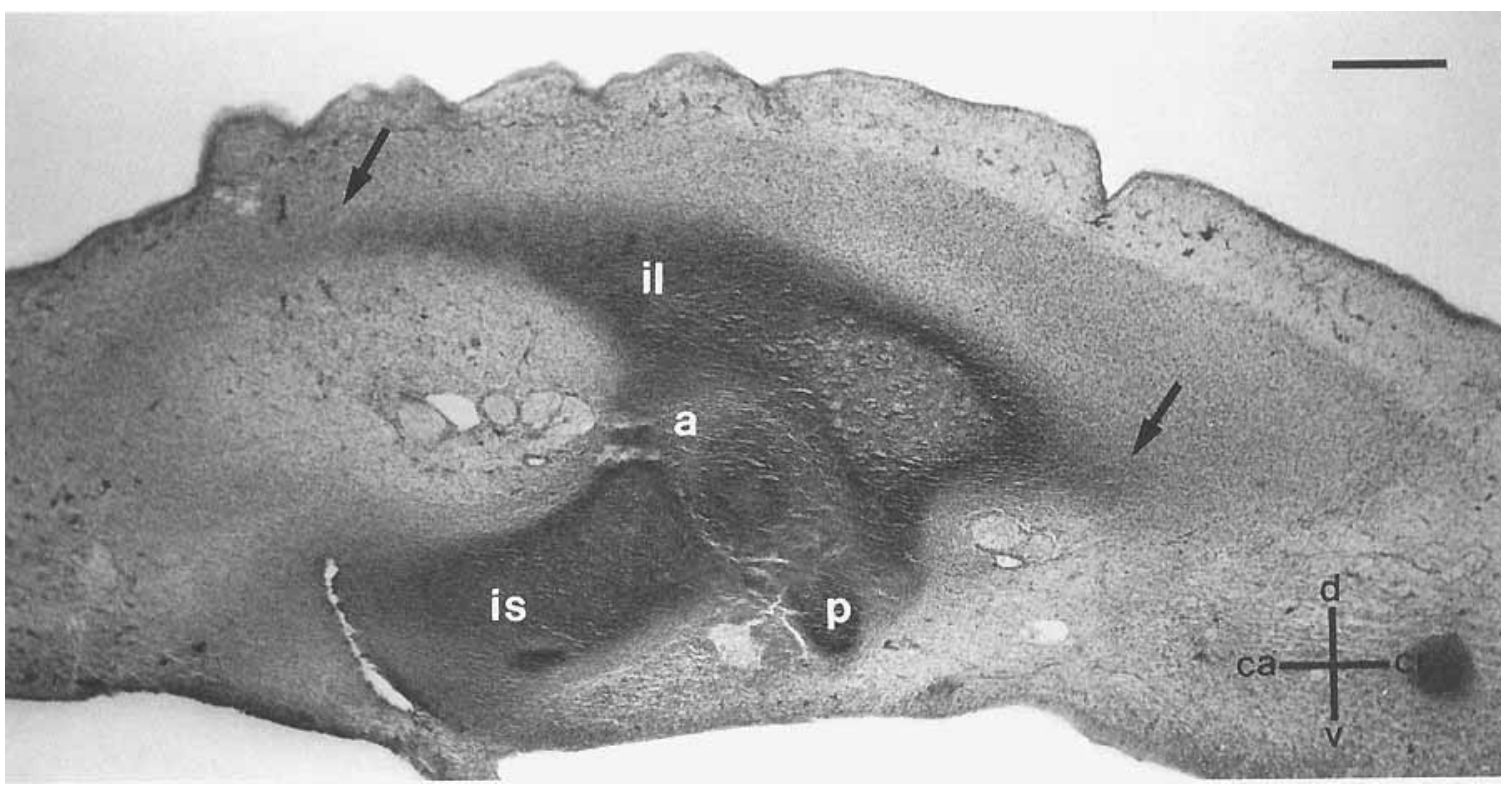

Fig. 4. Cross section through the pelvic girdle at stage 28.5. The pelvic girdle anlage stains darkly with Alcian blue around the acetabulum (a), but the cranial and caudal extents (arrows) are fibrous and blend into the surrounding mesenchyme. Bar $=100 \mu \mathrm{m}$.

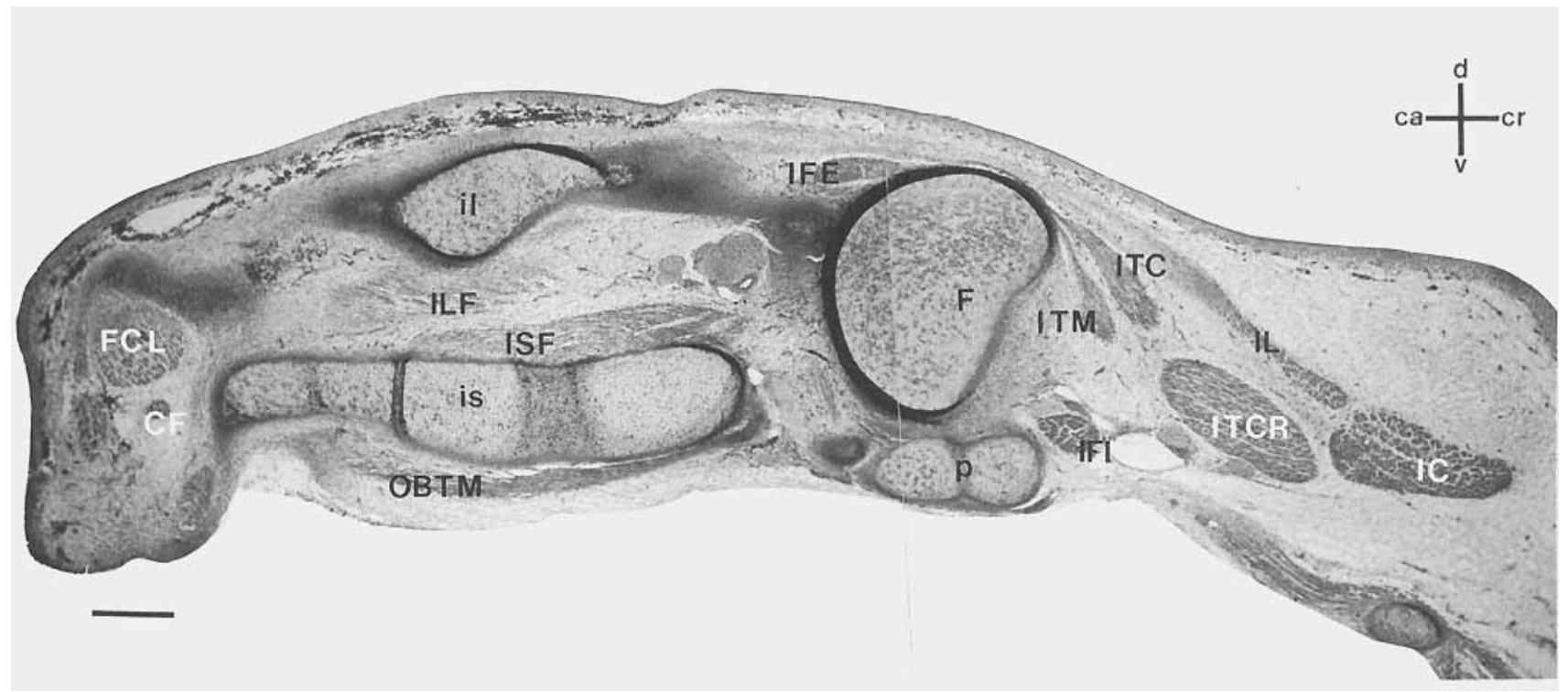

Fig. 5. Cross section through a proximal level of the thigh reconstructed in Figs. 12-16 (stage 32.5). The boundaries of the skeletal elements are well-defined by Alcian blue staining. Bar $=100 \mu \mathrm{m}$.

superficial, extend the entire length of the thigh, and form a continuous condensation after initial separations from the underlying deep proximal and femorotibialis groups. Connection with the underlying femorotibialis and iliofemoralis internus is retained for a short time, but the iliofemoralis internus is placed in the deep proximal group because of its position. The deep proximal group (Figs. 5, 7) includes iliofemoralis internus; the iliotrochantericus cranialis, medius, and caudalis; and iliofemoralis externus, which all originate just beneath the superficial muscles and insert on the proximal femur. More distally, the three heads of the femorotibialis, the femorotibialis group, arise on the shaft of the femur and extend to the lower leg just distal to the knee (Figs. 1, 2). These form a continuous, separate condensation except for a small connection to the iliotibialis group through the ambiens and the iliotibialis cranialis anlagen.

Muscles derived from the ventral muscle mass can be divided into an adductor group, a flexor group, and a caudal group based on location. The adductor group is composed of five muscles. Their anlagen form a contin- 


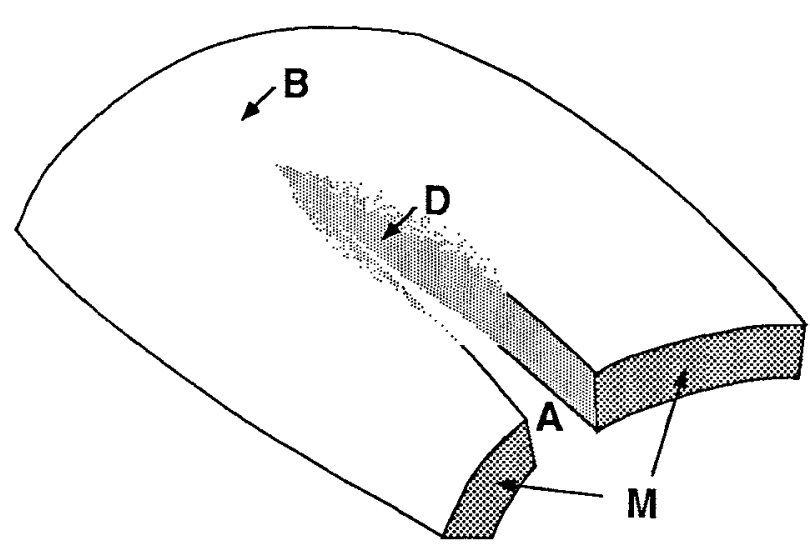

Fig. 6. Schematic diagram of the progression of a cleavage zone. Two muscles $(\mathrm{M})$ in the process of cleaving are diagrammed to illustrate the progression of the cleavage zone between them. In this case, distal is in the foreground where the separation process began. The positions of the letters indicate regions of the incipient cleavage zone before cleavage $(B)$, during cleavage $(D)$, and the cleavage zone after the muscles have cleaved (A).

uous mass extending from the pelvic girdle distally along the length of the femur. Proximally, fibers of the two obturators originate on the ischium and pubis, pass through the obturator foramen, and insert on the femur (Figs. 2, 5, 13, 15, 16). The two pubo-ischio-femorales originate on the dorsal ischium and insert on the femur (Figs. 1, 2, 8-10, 12-16, 19). The ischiofemoralis also arises on the ischium and passes cranially to insert on the head of the femur (Figs. 5, 15, 16, 19). The second group, the flexor group, is composed of flexor cruris lateralis pars pelvica, flexor cruris lateralis pars accessoria, and flexor cruris medialis (Figs. 10, 14-16). These primordia are intimately associated, and all originate postaxially. The third group, the caudal group, contains caudofemoralis and iliofemoralis (Figs. $5,9,10,19)$. These originate from the caudal portion of the pelvic girdle and insert on the caudal femur. The caudal group is closely associated with the flexor group, but caudofemoralis and iliofemoralis are placed in a separate group because they originate caudally and their anlagen are not discernible before stage 28 .

\section{Morphogenesis of Individual Muscle Groups}

In the discussion of each group, we describe 1) the position and relationship of the group to the pelvic girdle and other skeletal elements before cleavage at stage 27 (Fig. 3); 2) the pattern of innervation to help define the position of each muscle (Fig. 11); 3) the direction and timing of the cleavage zones that separate muscles within the group (Fig. 18); and 4) the morphology of the musculature after cleavage at stage 32.5 (Figs. 12-16).

Deep proximal group; iliofemoralis internus, iliotrochantericus medius, iliotrochantericus cranialis, iliotrochantericus caudalis, iliofemoralis externus

The deep proximal group anlage can first be recognized late in stage 27. It is separated from most of the iliotibialis group by loose connective tissue but is connected cranially to the iliotibialis cranialis anlage through the iliofemoralis internus (Fig. 17). Other classification schemes may include the iliofemoralis internus with the iliotibialis group, if the classification is based on timing of separation rather than position. The largest portion of the deep proximal group originates indistinctly near the preaxial region of the ilium, which is lightly stained by Alcian blue before stage 28 . The origins of the iliotrochantericus caudalis and iliofemoralis externus extend more caudally but are also indistinct (see Fig. 16 for illustration of origins). The distal end of this group nears the head of the femur, but there is no distinct insertion before stage 28 .

The deep proximal group receives innervation from both the crural and ischiadic nerve trunks. As the muscles start to cleave, the femoral nerve lies between the iliotrochanterici cranialis and medius at the cranial half of the boundary between them. These two muscles cleave on the caudal half of the boundary; their separation emerges above the nerve, independent of muscle nerve ingrowth (Fig. 7). A branch of the femoral nerve, N. coxalis cranialis, which passes between the iliotrochantericus medius and iliofemoralis internus anlagen, enters the iliofemoralis internus close to its origin. A more distal branch enters the remaining portion of the deep group from the cranial side and sends two branches proximally to innervate the iliotrochantericus caudalis and iliofemoralis externus. A branch of the ischiadic nerve also enters the iliofemoralis externus near its insertion and courses proximally within the muscle. The pattern of these muscle nerves supplying the iliotrochantericus caudalis and iliofemoralis externus anlagen is the same as in the adult. The nerves enable identification of the two anlagen before differences in muscle fiber direction can be detected as well as before and after muscle separation since these muscles are very closely apposed in the adult as well as in the embryo.

The initial separation of the deep proximal group from the overlying iliotibialis group isolates the iliofemoralis primordium from the remaining portion of the deep proximal anlage. This separation is complete before stage 28 and proceeds from distal to proximal as well as from posterior to anterior. A connection between the iliofemoralis internus and iliotibialis cranialis anlagen is maintained until stage 29 when they complete a distal to proximal cleavage. This observation differs from that of Romer, who described the separation of the iliofemoralis internus from the superficial muscles before separation from the other deep muscle anlagen. An indentation between the iliotrochanterici cranialis and caudalis at their superficial surface presages any apparent decrease in cell packing density in the presumptive cleavage area (Fig. 7). First, the former muscle separates from the underlying iliotrochantericus medius from distal to proximal by stage 29. Then, both simultaneously cleave from the iliotrochantericus caudalis in the same direction by stage 30 (Fig. 5 ).

Also by stage 30 , the closely apposed iliotrochantericus caudalis and iliofemoralis externus can be distinguished by fiber direction. Fibers composing the iliotrochantericus caudalis converge on a central tendon that passes through the center of the muscle and run parallel to the femur from the ilium to the dorsal head of the femur. Fibers of the iliofemoralis externus angle 

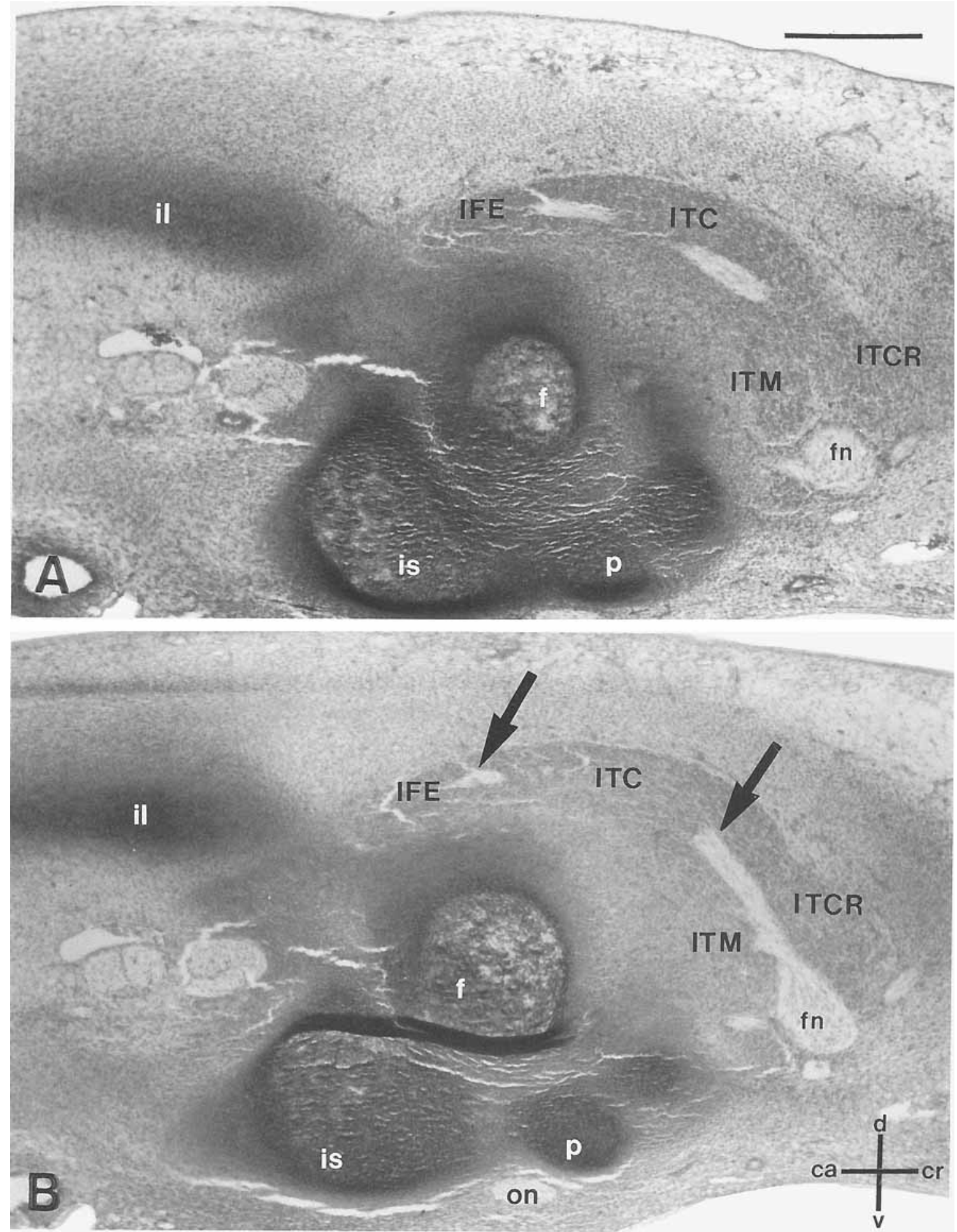

Fig. 7. Cross sections through a proximal portion of a stage 29 thigh showing the innervation and cleavage of the deep proximal group. In $\mathbf{A}$, the cleavage zone between the iliotrochanterici cranialis and medius begins proximally and has appeared in this section; the cleavage is therefore not initiated by the growth of the femoral nerve ( $\mathrm{fn}$ ) between these muscles, since this nerve courses between the muscles in a more distal position shown in $\mathbf{B}$. Despite the absence of a clear separation between the iliofemoralis externus and iliotrochantericus caudalis, the anlagen of these muscles can be identified by positions of their respective muscle nerves (arrows). on, Obturator nerve. Bar = $100 \mu \mathrm{m}$. 

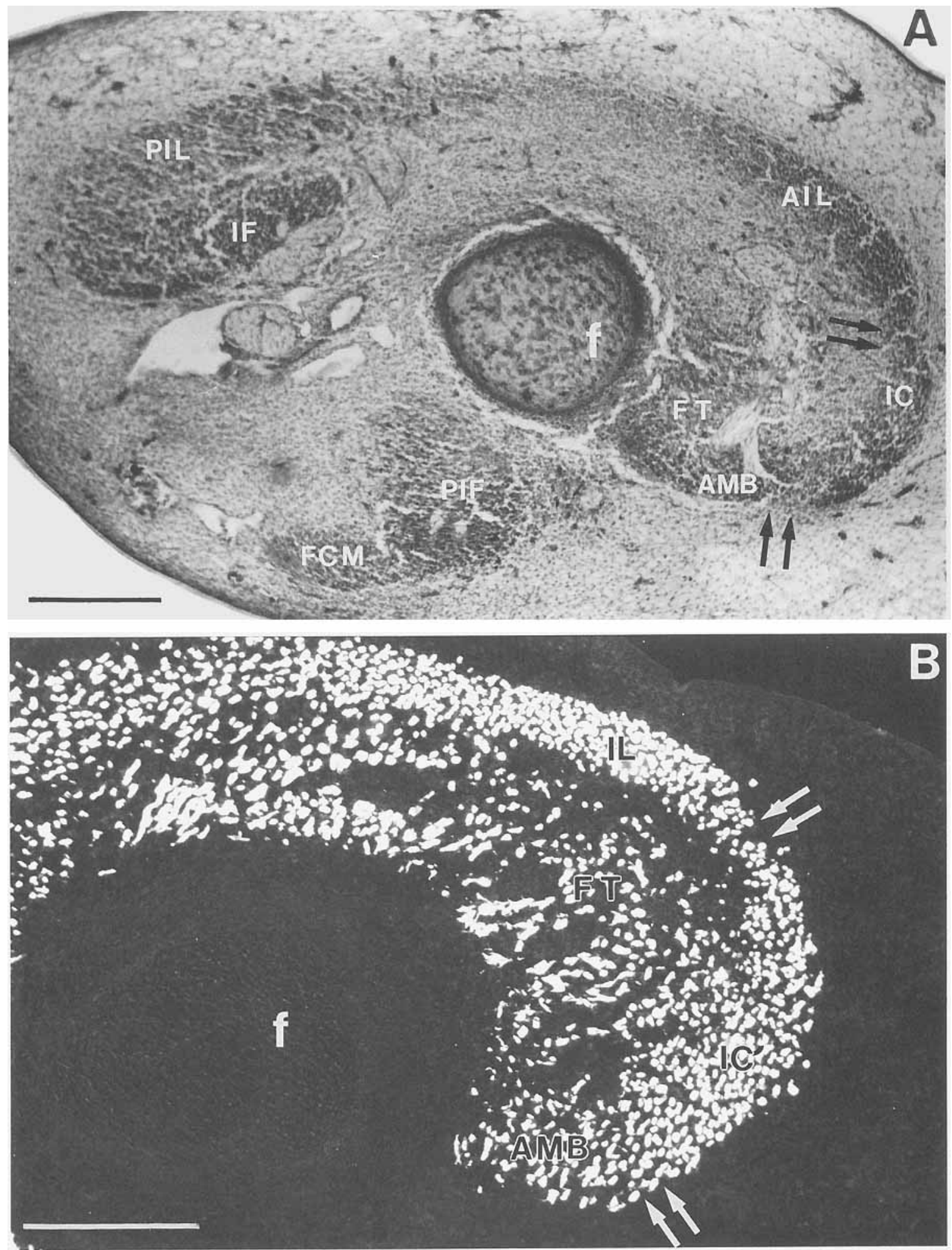

Fig. 8. Muscle masses and cleavage planes can be clearly visualized at the light microscopic level using conventional histological stains $(\mathbf{A})$ and the monoclonal antibody MF 20 which is specific for sarcomere myosin (B). Indentations at the boundary between the iliotibialis cranialis and lateralis (upper double arrows) accompany the formation of the cleavage zone between these two muscles. The lower double arrows denote the presumptive cleavage plane between the iliotibialis cranialis and the ambiens. Stage 28.5 embryo. Bars $=100 \mu \mathrm{m}$. 

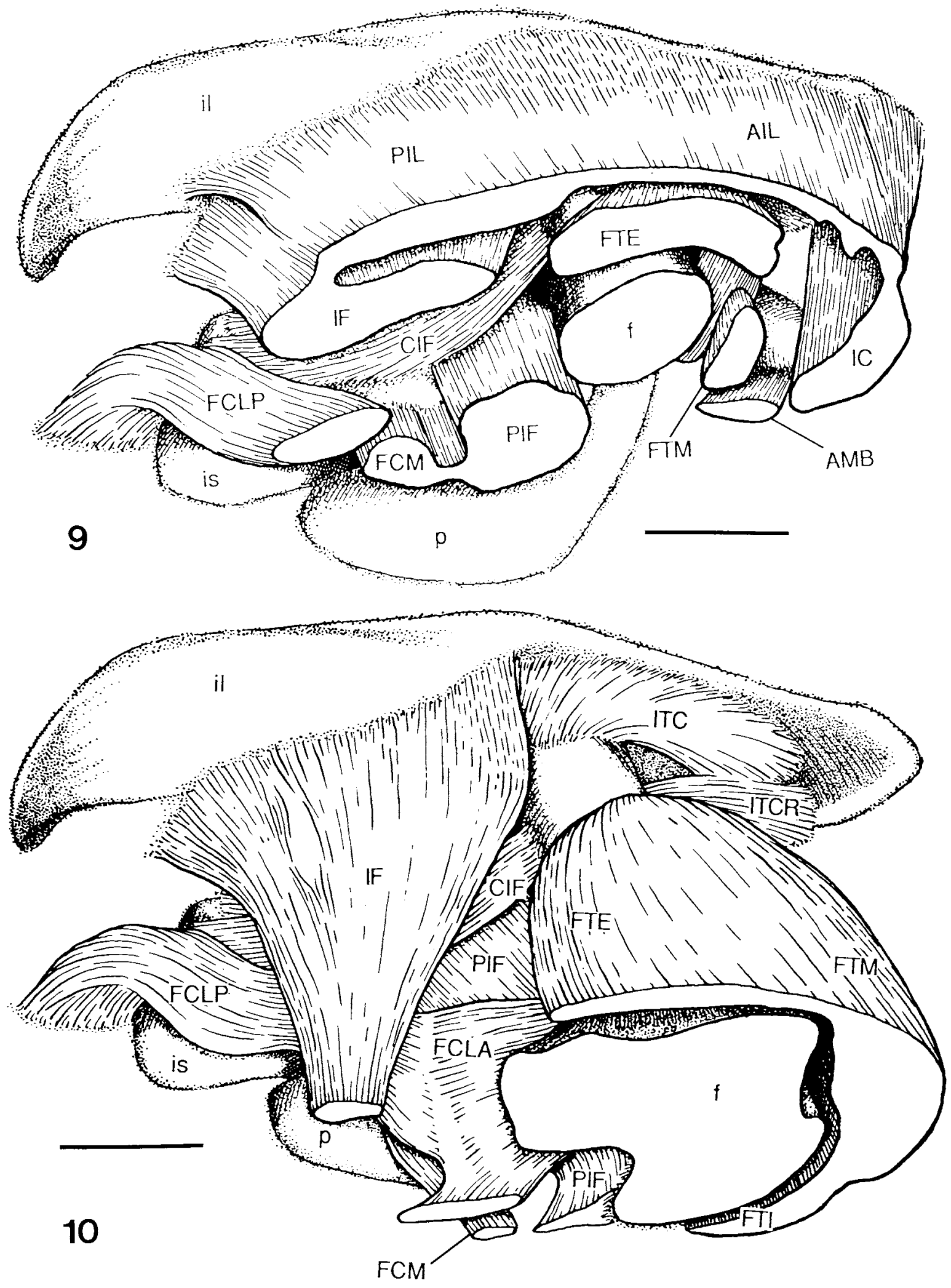

Fig. 9. Reconstruction of the thigh of a stage 29 embryo. Several pairs of muscles are in the process of cleaving: iliotibialis lateralis preacetabularis and iliotibialis cranialis, iliotibialis lateralis postacetabularis and iliofibularis, and flexor cruris medialis and the pubo-ischiofemorales. Bar $=0.3 \mathrm{~mm}$

Fig. 10. Dorsal surface of a stage 29.5 thigh with the iliotibialis lateralis and cranialis removed. Bar $=0.3 \mathrm{~mm}$. 


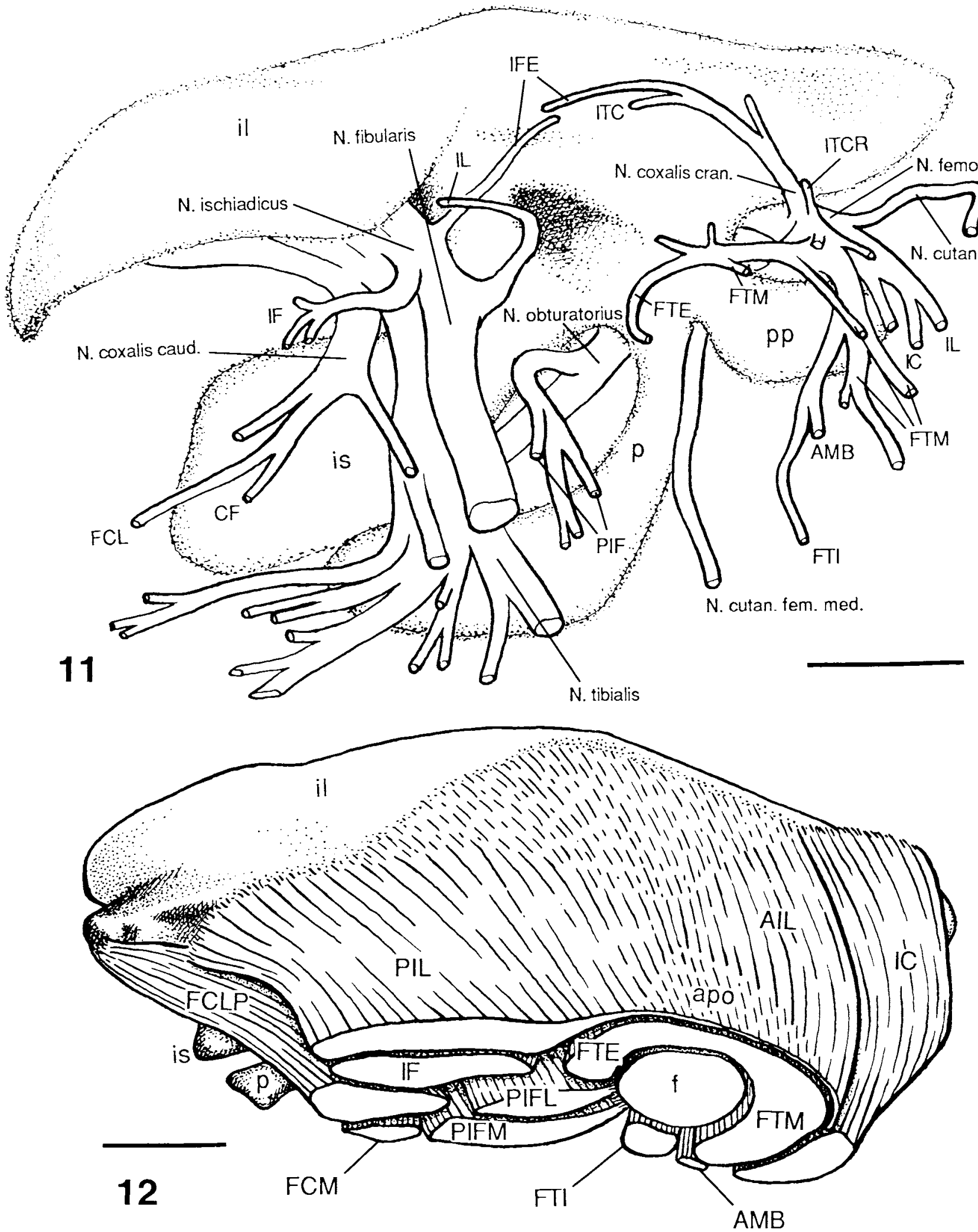

Fig. 11. Reconstruction of the pelvic girdle and nerve pattern of a stage 29 thigh. Muscle nerves are indicated by the abbreviations for the muscles which they innervate. pp, Pectineal process; $N$. cutan. fem. cran., lat., and med., N. cutaneus femoralis cranialis, lateralis, and medialis. Bar $=0.3 \mathrm{~mm}$.

Fig. 12. Muscles of the dorsal surface of the thigh in a stage 32.5 embryo. apo, Aponeurosis between the femorotibialis and the iliotibialis lateralis preacetabularis. Bar $=0.5 \mathrm{~mm}$. 

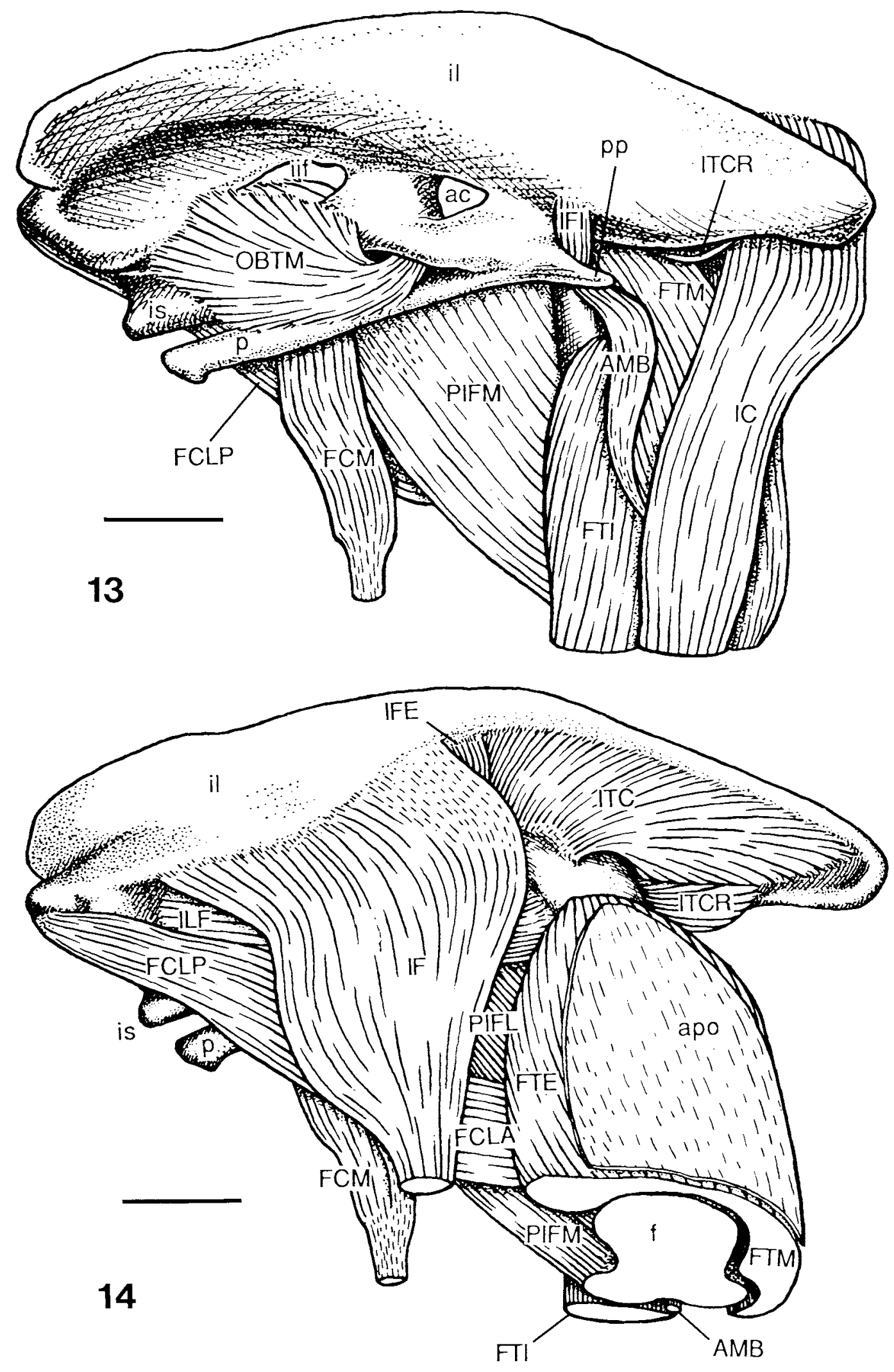

Fig. 13. Reconstruction of the thigh in a stage 32.5 embryo showing the muscles of the ventral surface (medial in the adult). ac, Acetabulum; iif, ilioischiadic foramen. Bar $=0.5 \mathrm{~mm}$.

Fig. 14. Second layer of muscles on the dorsal aspect of the thigh in a stage 32.5 embryo. The iliotibialis cranialis and iliotibialis lateralis have been removed. apo, Aponeurosis between the iliotibialis lateralis and the femorotibialis. Bar $=0.5 \mathrm{~mm}$. 


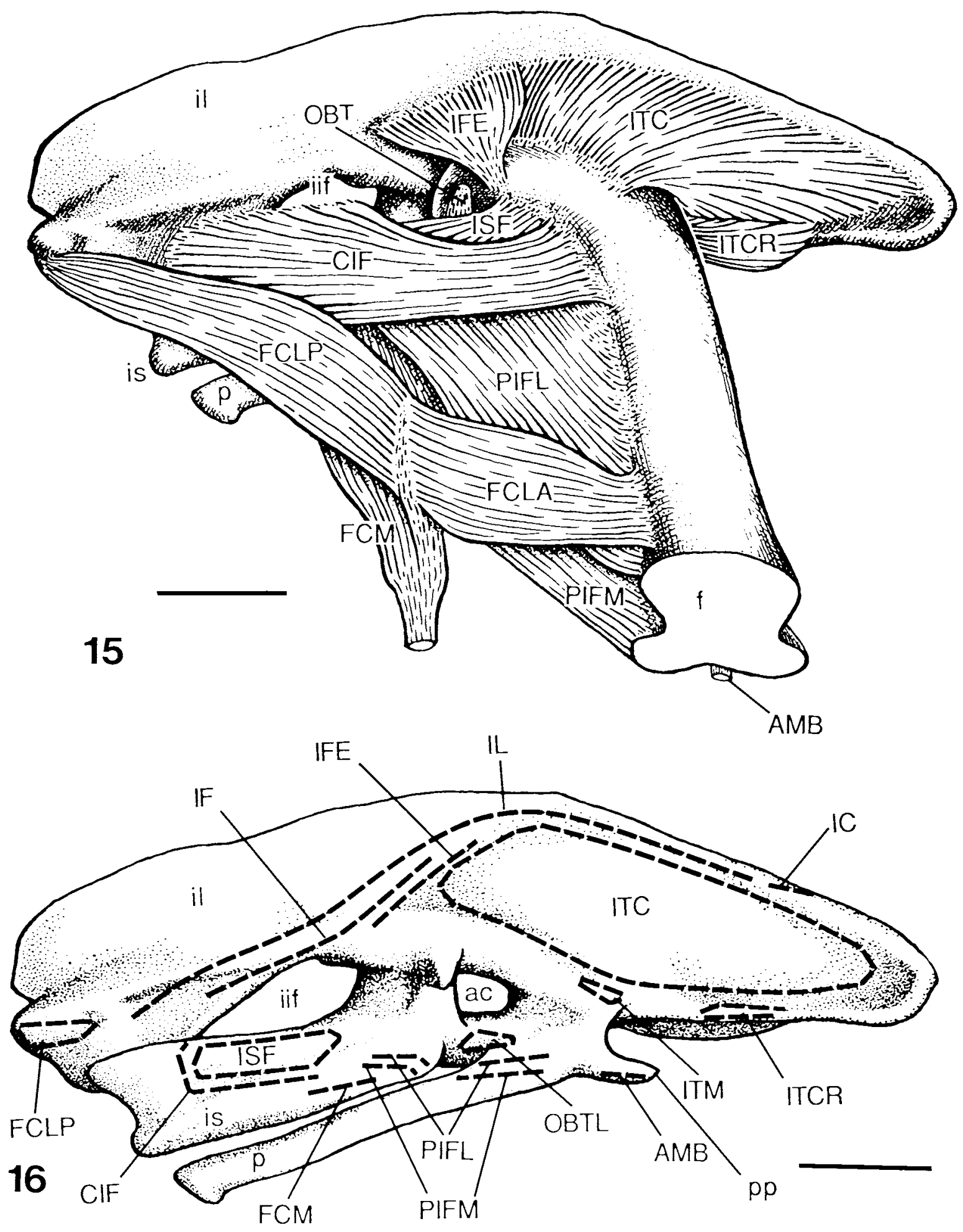

Fig. 15. Deep muscles on the dorsal aspect of the thigh in a stage 32.5 embryo. The iliotibialis cranialis, iliotibialis lateralis, femorotibialis, and iliofibularis have been removed. iif, Ilioischiadic foramen. Bar $=0.5 \mathrm{~mm}$.

Fig. 16. Reconstruction of the pelvic girdle of a stage 32.5 embryo with origins of muscles indicated by dotted lines. ac, Acetabulum; pp, pectineal process; iif, ilioischiadic foramen. Bar $=0.5 \mathrm{~mm}$. 

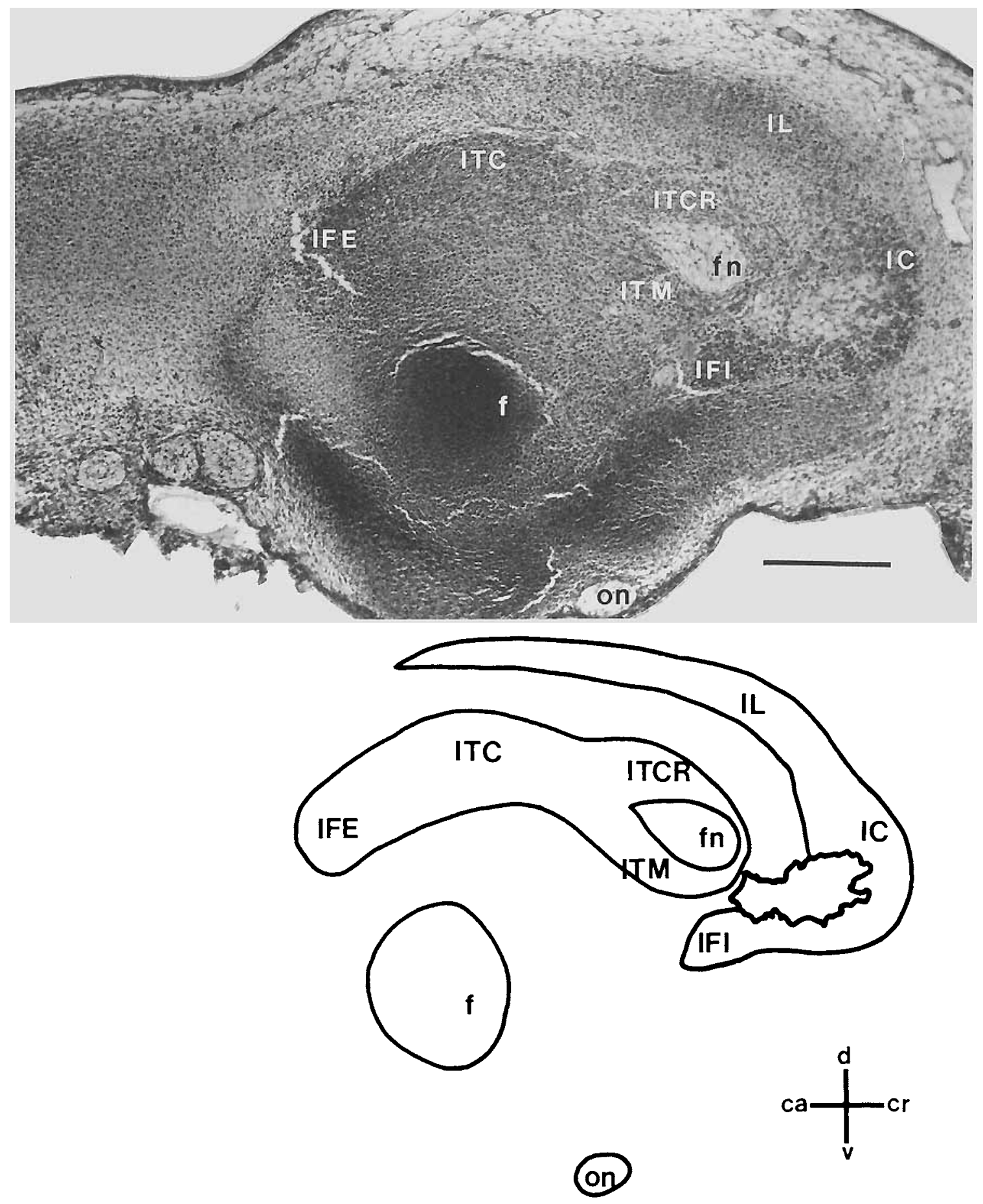

Fig. 17. Cross section through a proximal region of the thigh at stage 28 . The iliofemoralis internus is clearly separated from the deep proximal muscles while remaining continuous with the iliotibialis cranialis primordium of the more superficial iliotibialis group. Camera-lucida of section is shown below. $\mathrm{fn}$, Femoral nerve; on, Obturator nerve. Bar $=100 \mu \mathrm{m}$.

toward the iliotrochantericus caudalis running from the dorsal ilium to the femur. The boundary between these two muscles is delineated only by a change in fiber direction rather than by a region of blue-staining ECM that typically fills spaces between cleaving muscles. Since a space did not gradually appear between 
these muscles, it was impossible to identify the direction of cleavage.

After the deep proximal muscles are separated, origins and insertions of the separated muscles can be identified more precisely, even though the tendons and the cartilage of the girdle and femur are not yet fully differentiated. At stage 32.5 , the iliofemoralis internus originates on the preacetabular ilium near the acetabulum and inserts on the anteroventral aspect of the proximal femoral shaft. The remaining muscles of this group all originate on the ilium and insert on the dorsal femur. More precisely, the iliotrochantericus cranialis inserts distal to the insertions of the iliotrochantericus caudalis and iliotrochantericus medius; and the iliotrochantericus medius inserts underneath the iliotrochantericus caudalis. In addition, the insertion of the iliofemoralis externus lies deep to a muscle of the iliotibialis group, the iliofibularis.

Iliotibialis group: iliotibialis cranialis, iliotibialis lateralis, ambiens, iliofibularis

The iliotibialis group is readily distinguishable from other dorsally derived muscle anlagen by its much greater distal extent as well as the previously mentioned separation from the deep proximal muscles during stage 27. The cranial portion of this group, the anlagen of the iliotibialis cranialis and iliotibialis lateralis preacetabularis, arises indistinctly near the primordium of the ilium; whereas the caudal anlagen of the iliofibularis and iliotibialis lateralis postacctabularis arise near the primordium of the ilium postaxially. The anlage of the ambiens can be identified on the basis of its position deep to the iliotibialis cranialis and its innervation from the femoral nerve, but the proximal and distal boundaries are not distinguishable before stage 28 . The origin of the ambiens, the pectineal process of the pelvic girdle (Fig. 13), is revealed by Alcian blue staining during stage 28 . The distal extent of this entire group approaches the knee where the condensation of muscle cells fades into a mass of unorganized connective tissue.

Crural and ischiadic nerves both send branches to innervate muscles of the iliotibialis group. Cranially, a large subset of axons from the crural nerve trunk enters the iliotibialis cranialis very close to its origin. The ambiens muscle nerve also branches from the femoral nerve along with branches to the femorotibialis midway along the proximodistal axis of the thigh. Further distally, additional branches enter the iliotibialis lateralis (Fig. 19). Caudally, the ischiadic trunk enters the limb through the large ilioischiadic foramen. The foramen is open at the caudal extent of the pelvic girdle throughout the cleavage period. The nerve continues into the limb distally underneath the iliofibularis for a short distance before it branches to innervate this muscle close to its origin. At the same level, another branch passes around the cranial end of the iliofibularis and extends dorsally within the iliotibialis lateralis postacetabularis.

The separations within this group illustrate the spatial complexity of the cleavage pattern particularly well (Fig. 18). For instance, one muscle, the iliotibialis cranialis, cleaves on two of its borders in opposite directions. It cleaves from the iliotibialis lateralis preacetabularis from distal to proximal and from the am- biens from proximal to distal. Indentations at the border of the iliotibialis lateralis and cranialis presage their actual separation at this location (Fig. 19). The ambiens simultaneously cleaves from the femorotibialis from proximal to distal while the iliotibialis lateralis postacetabularis separates from the iliofibularis from anterior to posterior as well as from distal to proximal. Romer (1927) described a lingering connection between the iliotibialis lateralis and iliofibularis at their cranial ends, but we observed the last connection at their caudal ends. All of the separations are completed between stages 29 and 30 .

After cleavage, the origins and insertions of the muscles derived from the iliotibialis group are more precisely identifiable. The iliotibialis lateralis is a sheetlike muscle covering the dorsal surface of the thigh. The cranial component originates from the dorsal ilium as a thin sheet of connective tissue. The caudal component originates immediately adjacent to the connective tissue and overlies the iliofibularis originating on the ventral ilium. The iliotibialis cranialis arises on the ilium as well, but cranial to the iliotibialis lateralis preacetabularis; and the ambiens takes origin from the pectineal process cranial to the iliofemoralis internus. Farther distally, the iliotibialis lateralis forms a continuous condensation of muscle cells. Midway along the proximodistal axis of the thigh, the cranial portion of the condensation becomes very thin and is closely apposed to the underlying femorotibialis. This thin layer is the precursor of the aponeurosis between the iliotibialis lateralis and femorotibialis in the adult.

All of these superficial muscles insert tendinously on the proximal lower leg. The iliofibularis tendon passes through a loop of connective tissue, the ansa m. iliofibularis, at the posterodorsal aspect of the knee. On the other side, the very long and thin tendon of the ambiens is sandwiched between the iliotibialis cranialis and the femorotibialis as they approach the knee from the cranial side. The iliotibialis lateralis fibers insert distal to the knee both independently and via the aponeurosis overlying the femorotibialis.

Femorotibialis group: femorotibialis (externus, medius, and internus)

The anlage of the femorotibialis is a distinct condensation just after stage 27 . The unseparated condensation surrounds the dorsal, anterior, and ventral femur and is connected cranially to the superficial group through the anlagen of the medial head and the ambiens. The anlage of the medial head originates about one-third of the way down the shaft of the femur. The other two anlagen emerge slightly more distally as dorsal and ventral extensions of the femorotibialis medius. At this stage, the femorotibialis has no apparent connections with the femur and disappears near the femoral condyle. Only later in development do these muscles closely attach to the femur. The femoral nerve disperses into several branches near the proximal extent of this group. The remaining branches enter muscles of the iliotibialis group.

The femorotibialis separates from muscles of the iliotibialis group before any signs of internal separation. The first separation from the overlying iliotibialis lateralis is very rapid. The two groups are continuous condensations of muscle cells before stage 28 ; and as 
STAGE 28

Dorsal muscle mass

Ventral muscle mass

STAGE 29

Dorsal muscle mass

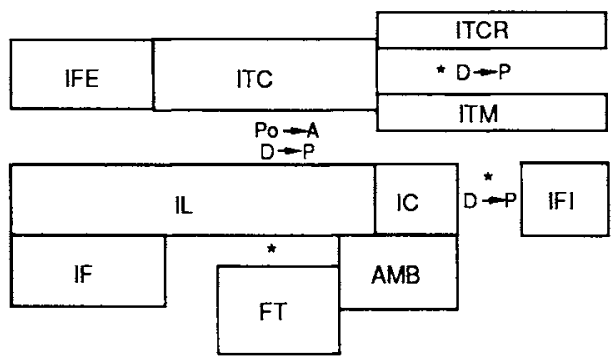

Ventral muscle mass

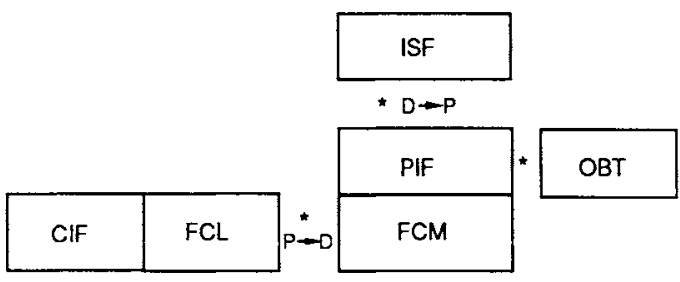

\section{STAGE 30}

Dorsal muscle mass

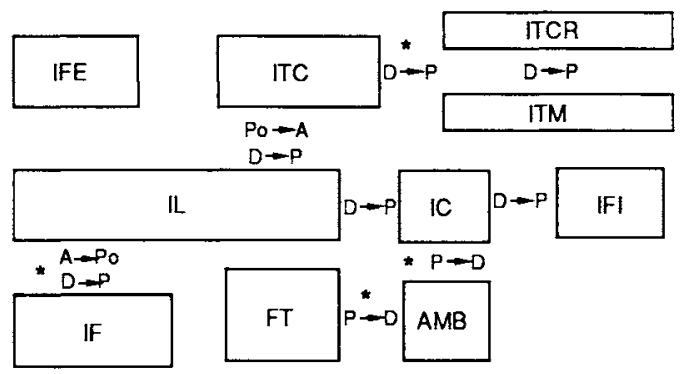

Ventral muscle mass

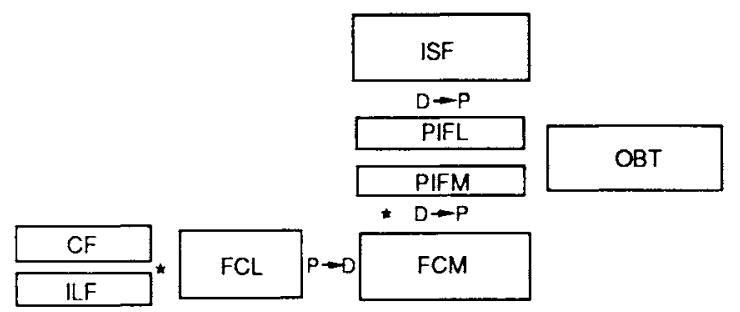

Fig. 18. Schematic diagrams of the sequence and pattern of muscle cleavage in the chick thigh. Each muscle is represented by a box (for abbreviations, see Table 1). At each stage, boxes that are touching denote uncleaved muscles; a space between boxes indicates that muscles have cleaved by that stage. New cleavages completed at each stage are indicated by an asterisk. The direction in which the cleavage zone progresses is indicated by an arrow; Po, posterior; A, anterior; P, proximal; D, distal. 

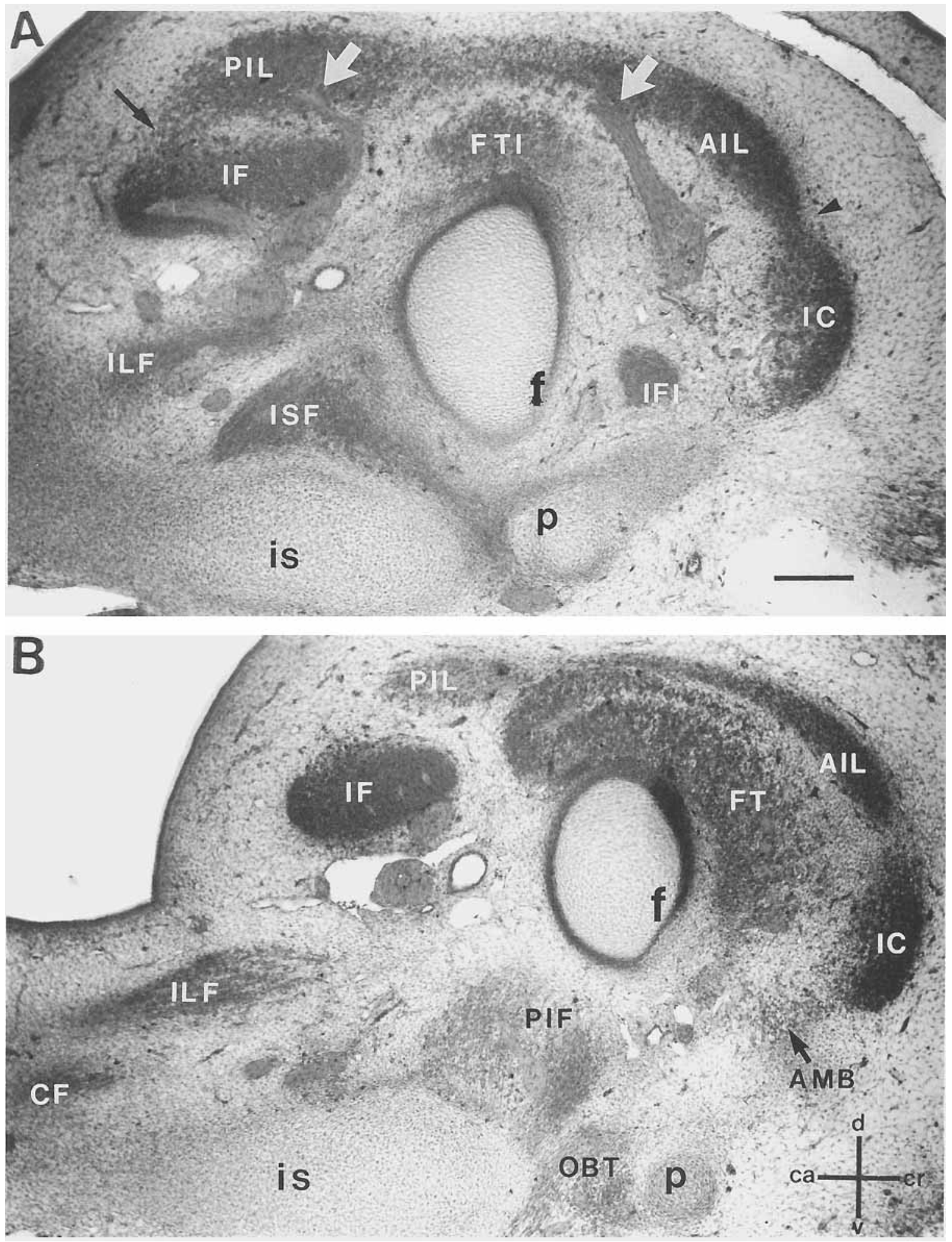

Fig. 19. Cross sections through a proximal region of the thigh of a plastic-embedded, stage 29 embryo. $\mathbf{A}$ is the most proximal section where the iliotibialis cranialis and iliotibialis lateralis preacetabularis are uncleaved; and $\mathbf{B}$ is from a more distal level where the two muscles are cleaved, showing that this cleavage zone progresses from distal to proximal. The separation of these two muscles is accompa- nied by an indentation at their cleaving border (arrowhead in A). Branches of both main nerve trunks (white arrows) course dorsally to innervate the iliotibialis lateralis. The iliofibularis and iliotibialis lateralis postacetabularis are nearly cleaved, but retain a connection at the posterior portion of their border proximally in A (black arrow). Bar $=100 \mu \mathrm{m}$ 
early as $4 \mathrm{hr}$ later, the groups are separated by loose mesenchyme at their dorsal border. The aponeurotic sheet of the iliotibialis lateralis seen in more mature limbs is not yet organized. Next, the ambiens separates from the femorotibialis medius anlage from proximal to distal before stage 30 . The three heads of the femorotibialis become distinct as indentations appear between them by stage 30 . These muscles are not separated by intervening space, and are similar in this respect to the arrangement of the iliotrochantericus caudalis and iliofemoralis externus. They are so closely connected that it is impossible to discern the direction of cleavage.

Even after stage 30, the three heads of the femorotibialis are still close together, but they resemble the adult morphology. The femorotibialis externus takes origin on the dorsal femur just distal to the insertion of the iliotrochantericus cranialis and continues a close association with the femur distally. Cranially, the boundary between the external and medial heads is indistinct. The femorotibialis medius arises from the cranial surface of the femoral shaft just distal to the insertions of the iliotrochanterici cranialis and medius. After passing under the iliotrochanterius medius, the femorotibialis medius joins the femorotibialis internus. The internal head is the smallest portion of the femorotibialis and originates from the ventral aspect of the distal two-thirds of the femoral shaft. All three heads are closely associated with the femur until they insert distally at the knee.

Adductor group: pubo-ischio-femoralis pars lateralis, pubo-ischio-femoralis pars medialis, obturatorius lateralis, obturatorius medialis, ischiofemoralis

The adductor group of a stage 27 embryo is not a discrete unit but is continuous cranially with the flexor group through a ventral connection between the puboischio-femorales and the flexor cruris medialis anlagen. The obturator anlage originates near the ischium and pubis and is continuous distally with the puboischio-femorales. The pubo-ischio-femorales originate near the ischium with the ischiofemoralis anlage and extend distally where they simply end at a mass of unorganized cells deep to a band of connective tissue proximal to the knee.

The obturator nerve and a branch of the ischiadic nerve innervate the adductor group. The obturator nerve branches from the crural nerve trunk and passes ventrally and caudally near the acetabulum before emerging between the pubis and ischium to innervate the obturator muscle. The nerve continues distally and enters the pubo-ischio-femoralis anlagen. The ischiofemoralis is innervated by the most proximal branch of the ischiadic nerve.

The first complete separations within the adductor group are between the ischiofemoralis and pubo-ischiofemorales and between the obturator and pubo-ischiofemoralis anlagen before stage 29 (Fig. 18). Since the obturators and pubo-ischio-femorales are connected only for a very short distance, no direction of cleavage was discerned. A similar situation arises with the ischiofemoralis and pubo-ischio-femorales. These also have a very short connection that simply disappears during stage 28 . Next the pubo-ischio-femorales become separated from each other by stage 30 and cleave from distal to proximal. Indentations at their deep and superficial edges demark the region of cleavage. The two obturator muscles are very closely connected even in the adult and are distinguished by their independent insertions on the proximal femur. These insertions become discernible at stage 30 .

After muscle cleavage, the morphology of the obturators and pubo-ischio-femorales resembles that of the adult. At stage 32.5 , the obturatorius medialis is a large, fan-shaped muscle that originates from the medial side of the ischium and the pubic ramus (Figs. 9, 15). Fibers pass ventral to the ischium through the developing obturator foramen and attach to a long tendon that inserts on the caudal side of the proximal femur. The obturatorius lateralis is a tiny muscle that originates on the lateral edges of the developing obturator foramen and inserts on the caudal surface of the femur underneath the obturatorius medialis insertion. The ischiofemoralis originates on the dorsal ischium on the rim of the large ilioischiadic foramen, ventral to the ischiadic nerve. Its fibers pass cranially to insert on the caudal, proximal femur distal to the tendon of the obturatorius medialis. The pubo-ischio-femoralis pars medialis is the larger of the two pubo-ischio-femorales and takes origin from the cranial ischium underneath the pubo-ischio-femoralis pars lateralis. The pubo-ischio-femoralis pars lateralis also arises from the cranial ischium, and both pubo-ischio-femoralis pars lateralis and pars medialis insert on the caudal femur just above the knee and underneath the flexor cruris lateralis pars accessoria of the flexor group.

\section{Flexor group: flexor cruris lateralis pars pelvica, flexor} cruris lateralis pars accessoria, flexor cruris medialis

During stage 27, the flexor primordia form an indistinct condensation joined to the adductor group posteroventral to the femur. No caudal or proximal extensions of the central condensation can be detected near the future origins of these muscles on the pelvis. The pelvis stains diffusely with Alcian blue at this time and blends extensively with the surrounding connective tissue. Individual muscle anlagen are not recognizable until after the onset of cleavage, and a caudal condensation extends from the main portion of the ventral muscle mass toward the tail.

The nerves supplying the flexor group originate from the ischiadic trunk. The $N$. coxalis caudalis diverges from the main trunk just distal to the proximal ischiofemoralis muscle nerve and travels distally and caudally between the iliofibularis and caudofemoralis muscles before entering the flexor cruris medialis and lateralis muscles.

The flexor group begins to separate internally during stage 28 before separating from the neighboring group. The flexor cruris lateralis completes a proximal to distal cleavage from the flexor cruris medialis by stage 29 , before the separation of the flexor group from the adductors. The condensation of the flexor cruris lateralis pars accessorius appears late in stage 28; and subsequently, before stage 29 , the flexor cruris lateralis pars accessorius is separated from the flexor cruris lateralis pars pelvica by loose connective tissue destined to become a raphe that forms a boundary between the two portions of the flexor cruris lateralis. The flexor group initiates its separation from the adductor 
group at the distal margin of the flexor cruris medialis and pubo-ischio-femoralis medialis anlagen. The cleavage zone progresses from distal to proximal, but an isthmus of muscle cells links the flexor cruris medialis and pubo-ischio-femoralis medialis until stage 30 , after the internal cleavage of the flexor cruris medialis from the flexor cruris lateralis in the opposite direction.

After cleavage, the origins and insertions of the flexor musculature are distinct. The flexor cruris lateralis pars pelvica originates on the caudal, terminal iliac process; passes dorsal to the flexor cruris medialis; and joins the flexor cruris lateralis pars accessoria at a compact condensation of connective tissue, the distal raphe. The fibers of the flexor cruris lateralis pars accessoria continue from the raphe and insert at a right angle on the caudal, distal femoral shaft. The flexor cruris medialis originates on the ischium and angles cranially to join the flexor cruris lateralis at the distalmost point of the raphe.

\section{Caudal group: caudofemoralis, iliofemoralis}

The morphogenesis of the caudal group is closely tied to that of the adductor group. At stage 27, the primordium of the caudo-ilio-femoralis is not distinguishable. The rudiment of the unseparated caudofemoralis and iliofemoralis appears caudally during stage 28 and is fused with the dorsal surface of the flexor cruris lateralis as they pass cranially toward the femur. Just distal to the ilioischiadic foramen, the second branch of the ischiadic nerve passes caudally to innervate muscles of this muscle group as the caudofemoralis and iliofemoralis approach the ischiadic trunk.

These muscles emerge very rapidly and have no obvious transition from a continuous mass of muscle cells to individual muscles. Several characteristics made their morphogenesis difficult to discern. First, the caudo- and iliofemorales are extremely thin muscles in their mature form. The smaller number of muscle cells in each muscle in the embryo coupled with the extreme thinness may have made the muscle condensation imperceptible amidst the loose mesenchyme of a young embryo. In addition, a mature iliofemoralis muscle contains a triangular window of transparent connective tissue underneath the ischiadic nerve midway between the origin and insertion. The iliofemoralis nearly disappears in cross-sections through this region and is undetectable in a young embryo.

It is possible that the caudo-ilio-femoralis anlage is joined to the ischiofemoralis early as reported by Romer (1927), but we see no morphological indications of the presence of two anlagen in this region at stage 27. Before muscles start to separate, the ischiadic nerve and its branches are widespread and form a field of fascicles between the ischiofemoralis anlage and the caudal part of the proximal thigh. Muscle fibers are imperceptible in the predicted location of the caudoilio-femoralis, and a muscle nerve branch to the caudoilio-femoralis is not identifiable either. The caudo-iliofemoralis anlage can later be identified during stage 28 as an extension of the dorsal portion of the flexor cruris lateralis anlage that approaches the caudoproximal surface of the femoral shaft. The intersection of the caudo-ilio-femoralis and flexor cruris lateralis is very short, so a direction of cleavage was not observed, but the muscles were distinct by late in stage 29 . In addi- tion, the caudo- and iliofemorales are so closely associated that a cleavage zone was not evident between this pair.

After cleavage, the muscles of this group lie nearly parallel with one another and at nearly right angles to the femur. At stage 32.5, the iliofemoralis originates from the ventral ilium, also on the rim of the ilioischiadic foramen, while the caudofemoralis originates on the Alcian blue-staining connective tissue near the pygostyle. The iliofemoralis lies dorsal to the caudofemoralis and becomes very thin as it passes ventral to the ischiadic nerve. The caudofemoralis passes between the flexor cruris lateralis and flexor cruris medialis caudally; and, as it approaches the femur, it joins the iliofemoralis so they insert together on the caudal proximal shaft of the femur.

\section{DISCUSSION \\ Sequence of Divisions}

The dorsal and ventral muscle masses of the chick thigh separate into individual muscles in the orderly sequence shown in Figure 18. The dorsal mass begins to cleave first as in the mouse thigh (Lance Jones, 1979), turtle shoulder (Walker, 1947), and lower leg of the chick (Wortham, 1948; but see Pautou et al., 1982). In the chick thigh, the iliotibialis lateralis anlage is the earliest to cleave as it separates from the underlying deep proximal and femorotibialis groups simultaneously by stage 28 . Some muscles of the ventral mass have just started to cleave by this time. By stage 29 , three separations are complete in the ventral mass along with two additional ones in the dorsal mass. The cleavage between the obturator and the pubo-ischiofemoralis anlagen as well as that between the ischiofemoralis and pubo-ischio-femoralis and between the flexor cruris medialis and lateralis are completed in the ventral mass during the same period in which the iliofemoralis internus becomes distinct from the iliotibialis cranialis and the iliotrochanterici cranialis and medius are separated in the dorsal mass. The remaining muscles are completely separated by stage 30 .

The orderly sequence is complex and cannot be reduced to a series of simple binary or trinary patterns like those indicated in the diagrams of Shellswell and Wolpert (1977), Pautou et al. (1982), and Romer (1927). Instead, continuous condensations of muscle cells representing groups of anlagen are complexly interconnected throughout the cleavage period (see also Cihák et al., 1989). Portions of muscles are often continuous with neighboring muscles as well as with those within a particular group. Indentations sometimes mark the incipient regions of division between muscle anlagen and give the muscle masses a lobed appearance, but the indentations appear as frequently within proposed groups as between them. Therefore, even though the lobes appear in a stereotyped sequence, they cannot be taken as a reliable indication of complete separation.

\section{Direction of Separations}

Each cleavage zone in the thigh emerges in a stereotyped direction. Muscles cleave along the proximodistal axis either from or toward their origins (Fig. 18). The majority of muscles in the thigh cleave toward their origins, from distal to proximal. Only three cleavage zones progress in the opposite direction: two in the 
dorsal mass and one in the ventral mass. The same pattern was seen in every embryo examined.

The progressive cleavage along the distal-proximal axis that we describe in the chick thigh is consistent with the less detailed descriptions of similar progressive separations within the developing musculature of the chick wing by Sullivan (1962) and within the chick lower leg by Wortham (1948). These investigators did not consistently describe all morphological features with equivalent detail, and intermediate phases of separation do not appear to have been included in their studies. However, their evidence can be construed to mean that cleavage is directional and, moreover, that cleavage zones start at either the muscle origins or at the insertions and proceed in the opposite direction. For instance, Sullivan (1962) describes the two portions of the latissimus dorsi as cleaved near the origin, but not at the insertion at one time point. In contrast, he also finds the opposite situation: the separation of several forearm muscles is incomplete in the region of the elbow in one embryo, suggesting that the cleavage zones had begun distally at the muscle insertions and had yet to progress far enough proximally to separate the muscles fully. Wortham (1948) describes a similar situation in which the middle layer of three deep ventral anlagen is separated only toward its distal end. The directional pattern inferred from these descriptions is consistent with our conclusion that limb muscles separate progressively along the proximodistal axis of the limb.

While we consistently see that cleavage begins at either end of the thigh and progresses in the opposite direction, other studies of the chick wing and lower leg strongly suggest that a large proportion of cleavage zones start in the center of the limb segment. Studies by Shellswell and Wolpert (1977) on the wing and by Pautou et al. (1982) on the lower leg report that muscles first separate in the proximodistal center of the limb segment and proceed outwards. In contrast, we report that none of the cleavage zones in the thigh start from the proximodistal center and proceed in both directions.

We think that the reports of separation from the middle to the ends may arise from misidentification of regions containing tendon primordia as regions of unseparated muscles. We observed that tendons do not become morphologically distinct until after muscles have separated (see also Wortham, 1948; Sullivan, 1962; Walker, 1947). The connective tissues that eventually link muscles to their sites of attachment lie at either end of the muscle. The boundary between muscle and the precartilage cells of skeletal rudiments is difficult to distinguish in these regions, especially at the onset of cleavage. If tendon primordia are included in the proximodistal extent of muscle tissue, it would appear as if cleavage zones start in the middle of a limb segment and proceed in both directions.

Our study of the thigh used techniques that allowed us to identify these tendon primordia. Visualization of embryonic connective tissue requires specialized staining procedures since the connective tissue and ECM of young embryos is not stained by the same procedures used for adult tissue. The relevant morphological features of the embryonic limb were revealed here by using a variety of fixing and staining procedures includ- ing one specific for embryos (Everett and Miller, 1973). We had the added advantage of confirming the distribution of muscle cells using a monoclonal antibody that specifically labels muscle cells. Wortham (1948) used a variety of fixing and staining procedures similar to those used in the present study. However, Pautou et al. (1982) used only one procedure, Bouin's fixative with Mallory's triple stain, which stains embryonic tissues in a variety of blues making them difficult to distinguish. Shellswell and Wolpert (1977) also reported the center-outwards direction of separation and did not mention the use of staining procedures specific for embryos. We suggest that re-examining the tissues in the wing and lower leg treated with stains that allow embryonic muscle and connective tissues to be distinguished clearly will resolve the controversy by showing the location of developing tendons relative to regions in muscle where cleavage is initiated.

Limb tissues are determined and mature from proximal to distal (see, for instance, Saunders, 1948; Bowen et al., 1989; Muneoka et al., 1989). The onset of cleavage within each segment of the limb is also ordered from proximal to distal. For example, lower leg muscles begin to separate later than those in the thigh (Wortham, 1948), and differentiation of the muscles is retarded in the manus (Sullivan, 1962). However, individual separations are not so ordered within each limb segment in the chick; cleavage zones progress from proximal to distal and from distal to proximal. Grim and Carlson (1974) reported a proximal to distal gradient of lengthwise separation within the developing axolotl hindlimb; but no other examples of muscle separation follow a uniform, proximal to distal pattern of differentiation. Therefore, separation patterns are not simple reflections of the proximal to distal pattern of limb maturation.

\section{Relationship Between the Pattern of Separation and Possible Causal Features}

We looked for correlation between the complex pattern of separation and a number of features that theoretically could control the pattern of cleavage. First, patterns of cleavage are not related to the positions of muscles within the thigh. For example, three superficial, neighboring muscles, the iliotibialis lateralis and cranialis and the ambiens, do not cleave in the same direction or at the same time. The iliotibialis cranialis cleaves from the iliotibialis lateralis from distal to proximal while on its opposite border it cleaves from the ambiens from proximal to distal. The only spatial order seen is that the dorsal muscle mass begins to cleave before the ventral mass, and four muscles of the deep proximal group separate from the superficial group en masse. Subsequent separations proceed in a spatial order that is unrelated to the position of the muscles within the limb. Common directions or timing of cleavages are not revealed when muscles are grouped according to their positions in the thigh (cranial vs. caudal, superficial or deep, dorsal or ventral).

Second, we find that the pattern of separations is not related to locations of blood vessels. Previous investigators have suggested that the vasculature may influence the pattern of musculature in the developing limb since muscle cells enter the limb at about the same time blood vessels are forming (see, for instance, Cap- 
lan and Koutroupas, 1973). If blood vessels played an active role in delineating the boundaries between individual muscles, one might expect that cleavage zones would contain blood vessels and the interior of muscles would remain relatively unvascularized. This is not the case. Individual muscles contain small vessels, and blood vessels cross cleavage zones and parallel them for short distances (Fig. 1). The vasculature is not restricted to cleavage regions, as would be expected if blood vessels delineated the cleavage pattern. In addition, a highly plastic system such as the vascular system is not likely to impose a pattern since it is responsive to change itself, such as angiogenesis during muscle hypertrophy. The vasculature pattern does not correlate spatially with and is not likely to impose the pattern in which muscles cleave.

Third, separation patterns are also unrelated to activity pattern. The initial partitioning of cells into dorsal and ventral muscle masses produces a general division into dorsal extensors and ventral flexors, but the ensuing separations do not further separate muscles by activity type as defined by the electromyographic data of Bekoff and Kauer (1984), Bekoff et al. (1987), Landmesser and O'Donovan (1984), Jacobson and Hollyday (1982a,b), and Gatesy (1989). Neither do extensors or flexors cleave in a consistent direction. Zones that progress in one direction (e.g., distal to proximal) separate muscles of all activity patterns. The timing of cleavages is unrelated to the distribution of muscles with a particular activity pattern as well. For example, the flexors iliotibialis cranialis and the iliotibialis lateralis preacetabularis cleave in the same direction and at the same time that extensors iliotrochantericus caudalis and iliotrochantericus medius are cleaving from each other and from the flexors iliotrochantericus cranialis and iliofemoralis externus. Common directions or timing of cleavages are not revealed when muscles are grouped according to their activity patterns.

Fourth, separation patterns are unrelated to the presence or pattern of innervation. Previous investigators have proposed roles for nerves in the process of muscle cleavage since the continued survival of motoneurons and muscles is mutually dependent. However, muscles separate normally without any neural influence. When nerves are prevented from growing into the limb by either chemical means (Shellswell, 1977) or by ablation (Lance-Jones and Landmesser, 1980), muscles cleave normally. The formation of nerve trunks does not depend on the presence of muscle either: the gross pattern of innervation is normal when muscle cells are prevented from entering the limb (Phelan and Hollyday, 1990). Since the initial processes of the morphogenesis of muscles and nerves have been shown to be mutually exclusive, nerves cannot play a role in the patterning of individual muscles although their presence is crucial for the formation of secondary myotubes.

Our observations on normal embryos also rule out a role for nerves in muscle separation. If nerves separate muscle masses by ingrowth, they could either grow along the entire cleavage zone or initiate a separation by entering the muscle masses at the point where cleavage starts. However, nerve branches between muscle anlagen intersect cleavage zones only for short distances, and they do not restrict their entry to points where muscles will begin to cleave. For instance, in Figure 7, the iliotrochanterici cranialis and medius are separated by a cleavage zone proximal to the branch of the femoral nerve that courses between them more distally to innervate the iliotrochantericus caudalis and iliofemoralis externus. The entrance point of this nerve is not correlated with the site of formation of the cleavage zone.

Wortham (1948) also observed that nerves lie between particular muscle anlagen in the lower leg, although her results have been misinterpreted by other investigators. Shellswell (1977) attributed a proposed mechanism to Wortham in which nerves cleave muscle masses as they grow between muscle anlagen. Wortham described three cases in which nerves "separated" or "divided" muscle masses into identifiable anlagen at single time points. Shellswell suggested that she meant separation was caused by "migration of nerves" rather than that the nerves were simply lying between two muscle anlagen. Wortham merely found that some nerves lie between muscle anlagen but made no suggestion of a role for innervation in muscle cleavage.

Fifth, separation patterns do not correlate with the formation of the connective tissue layers and ECM that envelop clusters of myotubes and individual muscles. Mayne et al. (1989) have suggested that the organization of ECM components into the basal lamina that surrounds myotube clusters, the endomysium, and the perimysium may play a major role in the morphogenesis of muscle. The formation of these tissues and their ECM components may accompany events late in morphogenesis, but these constituents of more mature muscle do not start to form until after muscles have separated. For instance, type IV collagen and laminin are diffusely distributed even at day 10 of development (Mayne et al., 1989), which is well after cleavage is complete. Other components of the ECM may play a role in muscle separation (see Schroeter and Tosney, 1991), but formation of the basal lamina around myotube clusters, the endomysium, and perimysium does not correlate temporally with the emergence of individual muscles.

\section{Relationship of Muscles to Skeletal Elements and Tendons}

The size and proportions of muscles and skeletal elements change during development, but by stage 32 , the arrangement of the musculature of the thigh closely resembles that of the adult (see also Pautou et al., 1982). Lanser and Fallon (1987) have suggested that the positional changes result from muscle primordia "migrating" apart from one another. We see no morphological evidence of migrating cells, and experimental manipulations suggest that there is little cell migration in the limb when muscles are separating (see, for instance, Tickle et al., 1978). In addition, condensed myogenic regions do not retain their size and move apart as the less densely packed cleavage zone emerges between two muscle primordia (Schroeter and Tosney, 1991). The positional changes of the muscles during their morphogenesis is most likely due to differential growth of individual muscles, chondrification of the skeleton, and mutual growth differences of single muscle primordia rather than to migration of entire muscle anlagen (see also Cihák, 1972; Sullivan, 1962). 


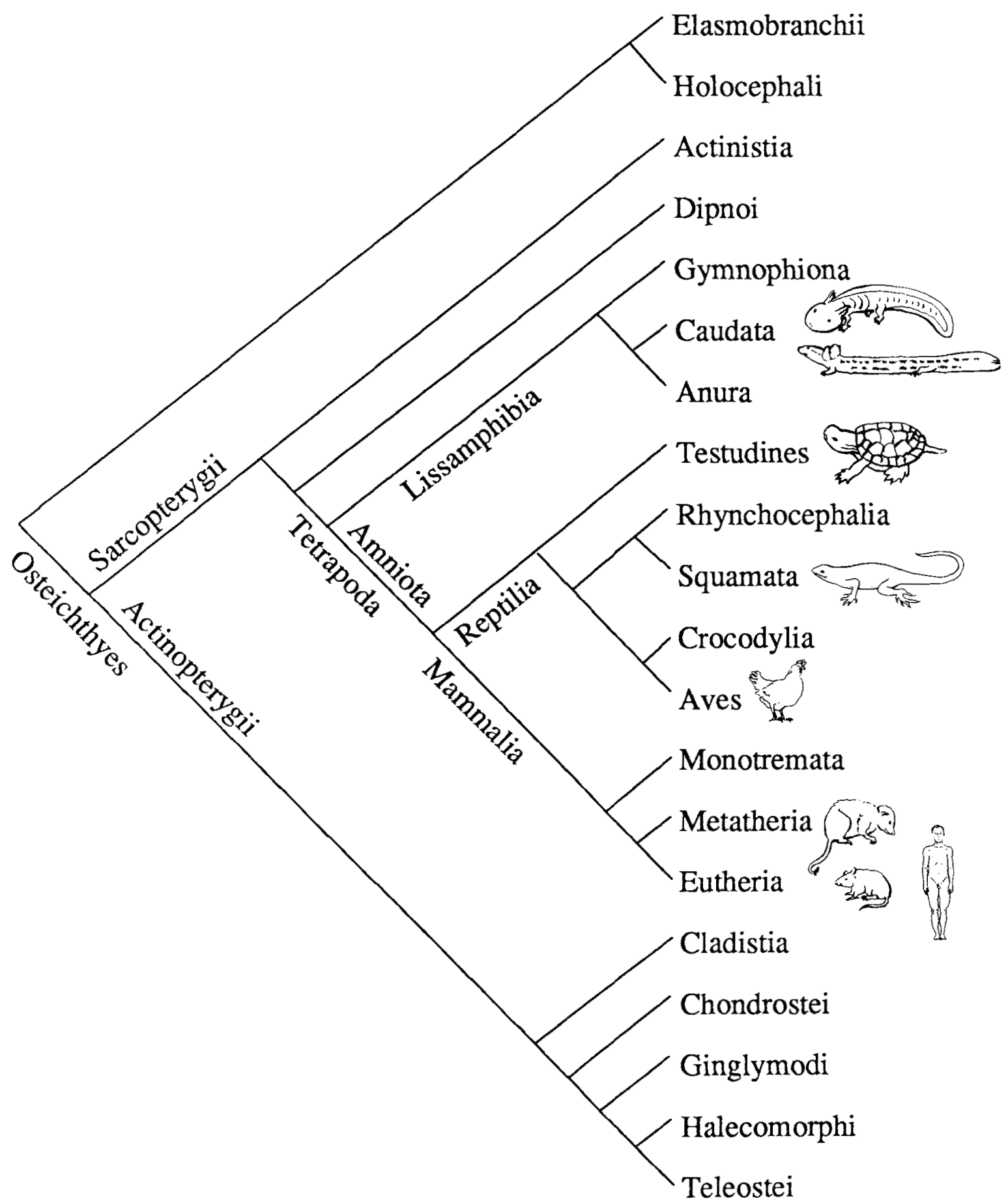

Fig. 20. Phylogenetic relationship among animals in which limb muscles are derived from dorsal and ventral muscle masses. The animals in which limb muscles are known to be derived from dorsal and ventral muscle masses include the newt, axolotl, turtle, lizard, opossum, mouse, human, and chicken. It is striking that the development of the limb in members of remote groups such as Caudata and Aves is

\section{Cleavage as a Criterion for Homology}

The embryological origin of tetrapod limb muscles seems to be from the dorsal and ventral muscle masses so similar. Examination of fin muscular development in members of Dipnoi or Elasmobranchii would provide insight into the changes that accompanied the evolution of the tetrapod limb. (Cladogram derived from Gauthier et al., 1988a,b; Lauder and Liem, 1983; Rosen et al., 1981; Fink, personal communication.)

(see Fig. 3; Romer, 1927, 1942; Lance Jones, 1979; Grim and Carlson, 1974; Walker, 1947; Chen, 1935; Cheng, 1955), but it has not been clearly shown how 
this common feature was derived. It is striking that even though newts are phylogenetically remote from lizards (Fig. 20), the development of their limb muscles is very similar. Romer (1922) presumed that tetrapod limb muscles are derived phylogenetically from the fish fin, which he reported has a relatively simple musculature arranged in dorsal and ventral muscle masses. While it is generally accepted that information derived from the study of ontogeny should provide insight into phylogenetic history, Romer made his statement without stating which fish he was referring to and without examining the development of any fish fins. Others have studied the progression of the apical ectodermal ridge and cell division in the trout fin (Bouvet, 1978; Geraudie and François, 1973), the skeletal structure of the fins of sturgeon (Sewertzoff, 1925) and lungfish (Holmgren, 1933), and the development of muscle in the Japanese medaka (Okamoto and $\mathrm{Ku}$ wada, unpublished observations); but no detailed information is available on the development of fin muscles of appropriate ancestral tetrapods.

Since the sequence of morphological changes that transform the dorsal and ventral muscle masses of the embryo into the adult musculature is similar to the morphological changes found in the course of phylogenesis, the emergence of muscle primordia during embryonic development has been used to determine limb muscle homologies. Muscle homologies have been based on a combination of embryological characteristics of morphogenesis including spatial and temporal patterns of separation and innervation patterns. Some aspects of these characteristics are difficult to define, and their usefulness and limitations as criteria for muscle homology are discussed below.

The spatial segregation patterns of muscle masses during development do not always coincide with the grouping of muscles by homology with ancestral muscles. Cleavage patterns have been represented incorrectly by several investigators as a series of binary or trinary separations of the muscle masses (see Romer, 1927; Pautou et al., 1982; Shellswell and Wolpert, 1977). As a result, proposed homologies based on the shapes and on the lobed, incomplete separations of intermediate primordia have been used to impose groupings on muscle anlagen that are continuous with their neighbors through condensations of muscle cells as well as to anlagen within the proposed group. These groupings have then been used circularly to reinforce homology arguments. Spatial segregation of portions of the muscle masses is not a reliable criterion for establishing homology.

Another way to define muscles for comparison among taxa is by the timing of divisions that completely separate one portion of a muscle mass from another. However, the determination of a precise sequence based only on the timing of complete separation is complicated. Since many muscles separate quickly and simultaneously, it is impossible to determine the exact sequence in which they all cleave. In addition, some muscles quickly separate nearly to completion and then retain a connection with neighboring muscles over a short portion of their boundaries until the end of the cleavage period. For example, the flexor cruris medialis is distinguishable from the pubo-ischio-femorales just after stage 28 but remains connected to them by a thin isthmus of muscle cells until stage 30 . Another example arises in the dorsal muscle mass. The iliotibialis lateralis postacetabularis and the underlying iliofibularis are distinguishable by shape before stage 29 , but the caudal one-third of the border between them remains continuous until stage 30 even though the cranial portion of the border is distinct by stage 29 (Fig. 19). A question arises whether muscles that are unseparated from each other but retain minor connections with neighboring groups constitute a group, or if a group is composed of unseparated anlagen that have no connections exterior to their own group. This ambiguity means that the timing of separations cannot be used alone as a criterion for homology.

Some primordia do separate completely to form a distinct group, and these separations may be useful criteria for homology. The initial cleavage between the deep proximal muscles and the superficial group is distinct but leaves a member of the deep proximal group, the iliofemoralis internus, not only completely separated from its original grouping which was based on location, but continuous with the superficial group (see Fig. 17). This and the separation of the three heads of the femorotibialis are the only separations that completely isolate a group of muscle primordia except for the initial partitioning of muscle cells into dorsal and ventral masses.

The remaining separations are distributed in a seemingly arbitrary, but reproducible order throughout the muscle masses. The separation of the femorotibialis group from the iliotibialis group approaches the neatness of the deep proximal separation, but a small connection is retained through the ambiens until stage 30 . The other cleavages are typified by more complex separation patterns. For example, the flexor cruris lateralis and medialis of the flexor group separate from each other before the flexor cruris medialis is fully separated from the adductor group. An internal separation (between muscles of the same group) is completed before an external one (between muscles of different groups). Few groups cleave as entities before they cleave internally. Other than the distinctness of the dorsal and ventral muscle masses and the subsequent isolation of the anlage of four of the deep proximal muscles and the femorotibialis, the timing of complete separations is a difficult criterion to use in grouping muscles.

A relationship between the spatial arrangement of muscles and their nerve supplies has been suggested as a way of tracing the evolutionary derivation of musculatures from simple muscle masses (c.f., Miner, 1925; Romer, 1927). Miner (1925) proposed that innervation of one muscle by distant sources, such as the two nerve trunks, arose as a result of the fusion of muscles that were originally innervated each by a single source. The resulting double innervation would be a more derived condition than a muscle innervated by one source. Romer (1927) presented an alternative explanation. He argued for multiply innervated ancestral muscles and the subsequent appearance of more complex musculatures from separations between areas of innervation. In this view, a double innervation would be the primitive condition. A possible way of distinguishing between these two possibilities is to examine the development of the fin musculature of lungfish or primitive 
sharks, which share a common ancestor with tetrapods (see Fig. 20). The fin may have intermediate developmental stages that reflect events in the evolutionary derivation of muscles from two opposing muscle masses and of their innervation patterns. For instance, if lungfish fins contained two muscles, each one derived from either a dorsal or a ventral muscle mass, and each mass had more than one source of innervation, then the view that double innervation is the primitive condition would be supported.

During development of the chick thigh, the sequence in which cleavage zones appear is unrelated to innervation patterns in a way that provides evidence for either Miner's or Romer's proposals. If single innervations were primitive and new muscles arose by fusion of singly innervated muscles, then we would have expected to see an initial separation of the doubly innervated iliofemoralis externus and then fusion of the two parts unless the condition is secondarily derived. AIternatively, if double innervations were more primitive and new muscles arose from separations between doubly innervated regions, then we would have expected to see first divisions between cranial and caudal portions of the dorsal muscle mass and not between superficial and deep portions unless the primitive condition of single innervation was just reappearing. However, we find that muscles do not first separate into regions innervated by opposing nerve trunks, nor do they separate and secondarily fuse. The sequence of cleavages in the chick thigh does not provide evidence for either argument.

Determining the value of a particular criterion for homology is especially evident in Rowe's (1986) argument for the homology of the avian iliofemoralis internus with the crocodilian pubo-ischio-femoralis internus pars medialis, another deep thigh muscle. Part of his argument was based on Romer's (1927) observation that the chick iliofemoralis internus separated from the superficial muscles with the other deep muscles en masse. Romer modified this description in his study of reptilian muscle development (1942) to include the iliofemoralis internus anlage with the superficial muscles instead of with the other deep muscles. He then homologized this muscle with the entire Lacertilian pubo-ischio-femoralis internus since a connection also persists between it and the cranial portion of a more superficial muscle group. This modification was based on muscle homologies rather than on a re-examination of the sectioned material, but the results of the present study confirm the modification: the iliofemoralis internus first cleaves from the rest of the deep proximal anlagen while remaining connected to the superficial group anlage (see Fig. 17). If the timing of cleavage of the iliofemoralis internus from the deep proximal muscles and from the more superficial group is the only criterion for homology, then Romer's view is supported.

Other, more easily identifiable criteria than the spatial separation patterns of muscle masses can more firmly support arguments for homology. Rowe (1986) described two other criteria for homology that are perhaps stronger indications that the iliofemoralis internus is at least a member of the deep proximal group. First, they have similar locations. All of the members of the deep proximal group lie in a deep position adjacent to the acetabulum, and they insert on the proxi- mal femur. Second, the iliofemoralis internus lies caudomedial to the femoral nerve like most of the deep proximal group. While separation patterns early in development, such as the partitioning of muscle cells into dorsal and ventral muscle masses and the separation of the femorotibialis, provide clear criteria for homology, later separations become complex and difficult to define as absolute separations. These later separations are details to which the idea that phylogeny is recapitulated in ontogeny has been applied too rigidly.

\section{Future Directions}

The thigh musculature of birds varies to some extent among species (see McKitrick, 1990, for a comprehensive review), and studying cleavage patterns may provide insight into the origin of the variation among the members of this single group. Muscles innervated by two nerve trunks may represent the failure of a primordium to cleave or a subsequent fusion of anlagen. For instance, adult kingbirds lack an iliotibialis lateralis postacetabularis (McKitrick, 1985). Is this a result of a failure of this anlage to develop? Does the primordium degenerate, or does it fuse with or fail to separate from a neighboring anlage? Adult roadrunners lack a caudofemoralis. What is the developmental history of this muscle? If these birds have gained an advantage by losing or acquiring a particular muscle in their evolutionary history, does the developmental sequence of the musculature reflect the evolutionary sequence of events that led to a particular change?

Modification of ontogenies is considered a plausible mechanism that can generate morphological changes since ontogeny generates most of the phenotype (see, for instance, Fink, 1982, 1988; Alberch, 1980). The role of this mechanism in the evolution of the tetrapod limb can be directly investigated if specifiable ancestors of tetrapods have living representatives that can be studied. Lungfish and primitive sharks fit this criterion (Fig. 20), and the ontogeny of their fin musculature could be compared with the ontogenies of a variety of tetrapod limbs. A detailed study of the development of the fin musculature would provide insight into the changes that accompanied the evolution of the tetrapod limb.

\section{ACKNOWLEDGMENTS}

We thank Kate Barald, Bruce Carlson, Steve Easter, Rich Hume, and Mary McKitrick for critical review of the manuscript; Steve Easter for instruction in recording the three-dimensional reconstruction data; Bill Fink for helpful discussions of ontogeny and phylogeny; and David Bay for photographic assistance. We acknowledge Steve Gatesy for the anatomical drawings and for discussions of bird thigh anatomy. We thank Eric Lombard for saving the century-old Lillie slide collection from the dumpster at the University of Chicago. Eric's rescue enabled the examination of the sections on which Romer based his 1927 study of chick thigh morphogenesis.

Funds for completion and presentation of this work were contributed by NIH grant 02138 to K.W.T., NIH training grant T32 HD-07274-04, the Department of Biology, the Rackham School of Graduate Studies, and an equipment grant from the OVPR. 


\section{LITERATURE CITED}

Alberch, P. 1980 Ontogenesis and morphological diversification. Am. Zool., 20:653-667.

Bader, D., T. Masaki, and D.A. Fischman 1982 Immunochemical analysis of myosin heavy chain during avian myogenesis in vivo and in vitro. J. Cell Biol. 95:763-770.

Baumel, J.J., A.S. King, A.M. Lucas, J.E. Breazile, and H.E. Evans, eds. 1979 Nomina Anatomica Avium. Academic Press, London.

Bekoff, A., and J.A. Kauer 1984 Neural control of hatching: fate of the pattern generator for the leg movements of hatching in posthatching chick. J. Neurosci., 4:2659-2666.

Bekoff, A., M.P. Nusbaum, A.L. Sabichi, and M. Clifford 1987 Neural control of limb coordination. I. Comparison of hatching and walking motor output patterns in normal and deafferented chicks. J. Neurosci., 7:2320-2330.

Bouvet, J. 1978 Cell proliferation and morphogenesis of the apical ectodermal ridge in the pectoral fin bud of the trout embryo (Salmo trutta fario L.). Wilhelm Roux Arch., 185:137-154.

Bowen, J., J.R. Hinchliffe, T.J. Horder, and A.M.F. Reeve 1989 The fate map of the chick forelimb-bud and its bearing on hypothesized developmental control mechanisms. Anat. Embryol. (Berl.), 179:269-283.

Caplan, A.I., and S. Koutroupas 1973 The control of muscle and cartilage development in the chick limb: the role of differential vascularization. J. Embryol. Exp. Morphol., 29:571-583.

Chen, H.K. 1935 The development of the pectoral limb of Necturus maculosus. Illinois Biol. Monogr., 14:1-71.

Cheng, C.-C. 1955 The development of the shoulder region of the opossum, Didelphys virginiana, with special reference to the musculature. J. Morphol., 97:415-471.

Cihák, R. 1972 Ontogenesis of the skeleton and intrinsic muscles of the human hand and foot. Adv. Anat. Embryol. Cell Biol., 46: $1-194$.

Cihák, R., M. Grim, and I. Dylevsky 1989 Morphological research of the locomotor apparatus. Czech. Med., 12:40-52.

Derby, M.A., and J.E. Pintar 1978 Histochemical specificity of Streptomyces hyaluronidase and chondroitinase $\mathrm{ABC}$. Histochem. J., 10:529-547.

Everett, M.M., and W.A. Miller 1973 Adaptation of Mallory's trichrome stain to embryonic and fetal material. Stain Technol., 48:5-8.

Fink, W.L. 1982 The conceptual relationship between ontogeny and phylogeny. Paleobiology, 8:254-264.

Fink, W.L. 1988 Phylogenetic analysis and the detection of ontogenetic patterns. In: Heterochrony in Evolution, M.L. McKinney, ed. Plenum Publ., New York, pp. 71-91.

Gatesy, S.M. 1989 Archosaur Neuromuscular and Locomotor Evolution. Doctoral Dissertation, Harvard University.

Gauthier, J., A.G. Kluge, and T. Rowe 1988a Amniote phylogeny and the importance of fossils. Cladistics, 4:105-209.

Gauthier, J., A.G. Kluge, and T. Rowe 1988b The early evolution of the Amniota. In: The Phylogeny and Classification of the Tetrapods. Vol. 1, Amphibians, Reptiles, Birds. Systematics Association Special Volume 35A, J.J. Benton, ed. Clarendon Press, Oxford, pp. 103-155.

George, J.C., and A.J. Berger 1966 Avian Myology. Academic Press, New York.

Geraudie, J., and Y. François 1973 Les premiers stades de la formation de l'ébauche de nageoire pelvienne de truite (Salmo fario and Salmo gairdneri). J. Embryol. Exp. Morphol., 29:221-237.

Grim, M., and B.M. Carlson 1974 A comparison of morphogenesis of muscle of the forearm and hand during ontogenesis and regeneration in the axolotl (Ambystoma mexicanum). II. The development of muscular pattern in the embryonic and regenerating limb. Z. Anat. Entwickl. Gesch., 145:149-167.

Hallmann, R., R.N. Feinberg, C.H. Latker, J. Sasse, and W. Risau 1987 Regression of blood vessels precedes cartilage differentiation during chick limb development. Differentiation, 34:98105.

Holmgren, N. 1933 On the origin of the tetrapod limb. Acta Zool., 14:185-295.

Humason, G.L. 1972 Animal Tissue Techniques, 3rd ed. Freeman. San Francisco.

Jacobson, R.D., and M. Hollyday 1982a. A behavioral and electromyographic study of walking in the chick. J. Neurophysiol., 48:238256.

Jacobson, R.D., and M. Hollyday $1982 \mathrm{~b}$ Electrically evoked walking and fictive locomotion in the chick. J. Neurophysiol., 48:257-270.

Lance Jones, C. 1979 The morphogenesis of the thigh of the mouse with special reference to tetrapod muscle homologies. J. Morphol., 162:275-309.

Lance-Jones, C., and L.T. Landmesser 1980 Motoneurone projection patterns in embryonic chick limbs following partial deletions of the spinal cord. J. Physiol. (Lond.), 302:559-580.

Landmesser, L.T., and M.J. O'Donovan 1984 Activation patterns of embryonic chick hind limb muscles recorded in ovo and in an isolated spinal cord. J. Physiol. (Lond.), 347:189-204.

Lanser, M.E., and J.F. Fallon 1987 Development of wing-bud-derived muscles in normal and Wingless chick embryos: a computer-assisted three-dimensional reconstruction study of muscle pattern formation in the absence of skeletal elements. Anat. Rec., 217: $61-78$.

Lauder, G.V., and K.F. Liem 1983 The evolution and interrelationships of the actinopterygian fishes. Bull. Mus. Comp. Zool., 150: 95-197.

Mayne, R., S. Swasdison, R.D. Sanderson, and M.H. Irwin 1989 Extracellular matrix, fibroblasts and the development of skeletal muscle. In: Cellular and Molecular Biology of Muscle Development, L.H. Kedes and F.E. Stockdale, eds. Alan R. Liss, Inc., New York, pp. 107-116.

McKitrick, M.C. 1985 Pelvic myology of the kingbirds and their allies (Aves: Tyrannidae). Ann. Carnegie Mus., 54:275-317.

McKitrick, M.C. 1990 A phylogenetic analysis of avian hind limb musculature. Misc. Publ. Mus. Zool., Univ. Mich. (in press).

Miner, R.W. 1925 The pectoral limb of Eryops and other primitive tetrapods. Bull. Am. Mus. Nat. Hist., 51:145-312.

Muneoka, K., N. Wanek, and S.V. Bryant 1989 Mammalian limb bud development: in situ fate maps of early hindlimb buds. J. Exp. Zool., 249:50-54.

Oster, F.G., N. Shubin, J.D. Murray, and P. Alberch 1988 Evolution and morphogenetic rules: the shape of the vertebrate limb in ontogeny and phylogeny. Evolution, 42:862-884.

Pautou, M.-P., I. Hedayat, and M. Kieny 1982 The pattern of muscle development in the chick leg. Arch. Anat. Microsc. Morphol. Exp., 71:193-206.

Phelan, K., and M. Hollyday 1990 Axon guidance in muscleless chick wings: the role of muscle cells in motoneuronal pathway selection and muscle nerve formation. Dev. Biol., 10:2699-2716.

Pratt, R.M., M.A. I arsen, and M.C. Inhnston 1975 Migration of cranial neural crest cells in a cell-free hyaluronate-rich matrix. Dev. Biol., 44:298-305.

Romer, A.S. 1922 The locomotor apparatus of certain primitive and mammal-like reptiles. Bull. Am. Mus. Nat. Hist., 46:517-606.

Romer, A.S. 1927 The development of the thigh musculature of the chick. J. Morphol., 43:347-385.

Romer, A.S. 1942 The development of tetrapod limb musculaturethe thigh of Lacerta. J. Morphol., 71:251-298.

Rosen, D.E., P.L. Forey, B.G. Gardiner, and C. Patterson 1981 Lungfishes, tetrapods, paleontology, and plesiomorphy. Bull. Am. Mus. Nat. Hist., 167:163-275.

Rowe, T. 1986 Homology and evolution of the deep dorsal thigh musculature in birds and other reptilia. J. Morphol., 189:327-346.

Saunders, J.W., Jr. 1948 The proximo-distal sequence of origin of the parts of the chick wing and the role of the ectoderm. J. Exp. Zool., 108:363-403.

Schroeter, S. 1989 Spatial and temporal patterns of muscle cleavage in the chick thigh. Am. Zool., 29:74A (abstr.).

Schroeter, S., and K.W. Tosney 1987 Formation of individual muscles in the chick thigh. Soc. Neurosci. Abstr., 13:253.

Schroeter, S., and K.W. Tosney 1989 Timing and direction of muscle cleavage in the chick thigh. Soc. Neurosci. Abstr., 15:373.

Schroeter, S., and K.W. Tosney 1991 Ultrastructural and morphometric analysis of the separation of two thigh muscles in the chick. Am. J. Anat. (this issue).

Sewertzoff, A.J. 1925 Development of the pelvic fins of Acipenser ruthenus. New data for the theory of the paired fins of fishes. J. Morphol. Physiol., 41:547-579.

Shellswell, G.B. 1977 The formation of discrete muscles from the chick wing dorsal and ventral muscle masses in the absence of nerves. J. Embryol. Exp. Morphol., 41:269-277.

Shellswell, G.B., and L. Wolpert 1977 The pattern of muscle and tendon development in the chick wing. In: Vertebrate Limb and Somite Morphogenesis, D.A. Ede, J.R. Hinchliffe, and M. Balls, eds. Cambridge University Press, Cambridge, pp. 71-86.

Sullivan, G.E. 1962 Anatomy and embryology of the wing musculature of the domestic fowl (Gallus). Aust. J. Zool., 10:458-516.

Tickle, C., A. Crawley, and M. Goodman 1978 Cell movement and the mechanism of invasiveness: A survey of the behavior of some normal and malignant cells implanted into the developing chick wing bud. J. Cell Sci., 31:293-322.

Walker, W.F., Jr. 1947 The development of the shoulder region of the turtle, Chrysemys picta marginata, with special reference to the primary musculature. J. Morphol., 80:195-249.

Wortham, R.A. 1948 The development of the muscles and tendons in the lower leg and foot of chick embryos. J. Morphol., 83:105-148. 